\title{
Catálogo e um Guia para orientar analistas web na construção de sites governamentais para o entendimento de informações gráficas para cidadãos cegos à luz da transparência da informação
}

\author{
João Marcelo dos Santos Marques ${ }^{12}$, Simone B. Leal Ferreira ${ }^{1}$, Claudia Cappelli ${ }^{1}$ \\ ${ }^{1}$ Departamento de Informática Aplicada - Universidade Federal do Estado do Rio de \\ Janeiro (UNIRIO)
}

Av. Pasteur 458, Urca, 22290-240, Rio de Janeiro - RJ - Brazil

${ }^{2}$ Instituto Brasileiro de Geografia e Estatística (IBGE)

Av. Franklin Roosevelt, 166, Castelo, 20021-120, Rio de Janeiro - RJ - Brazil

\{joao.marques, simone, claudia.cappelli\}@uniriotec.br

\begin{abstract}
A variety of information and services are disseminated on the web, enabling citizens to become aware. But with the advancement of the internet and the need for information transparency, many organizations still do not care about the information provided in the form of graphics so that certain groups of citizens can understand them, such as the blind. The objective of this work is to identify the main difficulties related to the comprehension of graphic information in governmental sites for the blind. In order to reach the proposed objective, an evaluation was carried out with blind volunteers performing tasks on bar, line and pizza type graphs in governmental sites and as contribution two artifacts were proposed: a catalog of understanding of the graphic information for blind citizens and a guide on how to use this catalog to guide the professionals involved in publishing graphic information to make them intelligible to these citizens. The validation of these products was carried out by analysts with experience in developing accessible websites.
\end{abstract}

Keywords. Accessibility; Graphics information understanbility; Transparency.

Resumo. Uma variedade de informações e serviços são divulgados na web, permitindo que os cidadãos se conscientizem. Porém com o avanço da internet e a necessidade de transparência da informação, muitas organizações ainda não se preocupam com as informações fornecidas sob a forma de gráficos para que certos grupos de cidadãos possam compreende-las, como os cegos. O objetivo deste trabalho é identificar as principais dificuldades relacionadas à compreensão de informações gráficas em sites governamentais para cegos. Para atingir o objetivo proposto foi realizado uma avaliação com voluntários cegos realizando tarefas em gráficos do tipo barra, linha e pizza em sites governamentais e como contribuição foram propostos dois artefatos: um catálogo de compreensão da informação gráfica para cidadãos cegos e um guia sobre como usar este catálogo para orientar os profissionais envolvidos na publicação de informações gráficas para torná-las inteligíveis para esses cidadãos. A validação desses produtos foi realizada por analistas com experiência em desenvolvimento de sites acessiveis.

Palavras-Chave. Acessibilidade; Entendimento de informações gráficas; Transparência. 


\section{Introdução}

Organizações que atuam em diversos segmentos do mercado disponibilizam uma variedade de informações, como produtos, ações administrativas, orçamentos públicos para a sociedade civil que foram impulsionadas pela utilização das tecnologias de informação e comunicação, as TICs, que proporcionaram o estímulo ao uso e a ampliação da participação de quaisquer usuários para acessar uma grande variedade destas informações. Alguns indivíduos, como os cegos, têm muita dificuldade de obter informações em ambientes que utilizam páginas web. Nesse ambiente são utilizados muitos gráficos e figuras que contém informações que não podem ser compreendidas por esses usuários, e não podem ser interpretados por tecnologias assistivas que utilizam discurso sintetizado ou em Braile. Dessa forma é necessário que sejam desenvolvidos mecanismos que permitam aos cegos terem acesso às informações dispostas nesses elementos [Yu et al. 2002]. Nesse sentido Takagi et al. (2007) reiteram que no caso dos gráficos de informação (como gráficos de linhas, gráficos de barras, gráficos circulares) podem apresentar dados inacessíveis às pessoas com deficiência visual, especialmente para os cegos, impactando no entendimento desses dados e podendo impactar na produtividade para a realização de suas atividades.

Em plena era da transparência, muitas vezes, ainda não se têm o cuidado de proporcionar textos que possam ser lidos por ferramentas, como os leitores de tela (programas que fazem a leitura do código HTML de páginas web e repassam aos deficientes visuais, através de voz humana sintetizada). Essa falta de preocupação é relatado por Geraldo et al. (2013) ao afirmarem: "não basta que sejam adicionados textos alternativos às figuras; esses textos devem transmitir uma mensagem que seja inteligível para seus usuários". Os deficientes visuais não são poucos, almejam e têm o direito à informação que é assegurada por diversas normas jurídicas, como a lei de acesso à informação - LAI [Brasil, Lei $\mathrm{n}^{\mathrm{o}} 12.527$ 2011], e por diretrizes e recomendações de acessibilidade. $\mathrm{O}$ número de cegos pode ser evidenciado nos dados divulgados pelo IBGE (Instituto Brasileiro de Geografia e Estatística) na pesquisa do Censo Demográfico de 2010, onde foi retratado que 506,3 mil dos 6,6 milhões de entrevistados declararam que são cegos [IBGE, 2016].

O presente trabalho, de cunho exploratório e qualitativo, teve como objetivo identificar as dificuldades no entendimento de informações gráficas em sites de governo pelos cidadãos cegos para propor recomendações para a elaboração de interfaces web que possibilitem a compreensão destas informações para esse grupo de indivíduos. Para atingir objetivo proposto foram realizados estudos das características do Catálogo de Transparência [Cappelli, 2009], foi feita uma identificação dos critérios do [E-MAG, 2014] relacionados ao entendimento de imagens por cidadãos cegos e por fim realizado um estudo de caso com voluntários cegos que executaram tarefas visando a identificação de informações em gráficos do tipo (barra, linha e pizza) em sites governamentais. Como recomendações foram produzidos dois artefatos: o Catálogo de Entendimento de Informações Gráficas para Cidadãos Cegos e um Guia de Validação desse catálogo. Os produtos gerados foram validados por analistas participantes com experiência em desenvolvimento de sites governamentais. Cabe ressaltar que no estudo de caso as características de transparência da informação, como adaptabilidade, clareza, completeza, explicação e intuitividade foram identificadas com base no levantamento bibliográfico. Um dos achados importantes nesse estudo foi a descoberta de duas novas características de transparência: detalhamento (relevante para fornecer 
informações, como o maior e menor valor, intervalo de valores nos eixos horizontal e vertical, etc.) e rastreabilidade (para descrever a proveniência dos dados, como a data, a hora que foram atualizados, criados os dados, a fonte da publicação, etc.).

Nesse contexto, o trabalho está organizado da seguinte forma: a seção 2 descreve a fundamentação teórica, abordando a transparência organizacional, a acessibilidade e os trabalhos relacionados. A seção 3 é retratado o Método de Pesquisa que foi utilizado. Na seção 4, são detalhadas as Observações com os Usuários identificando as principais dificuldades na compreensão de informações gráficas durante a realização das tarefas nos gráficos de barras, linhas e pizza. A seção 5, é compilada a Análise dos Resultados. A seção 6 e 7, abordam as Recomendações para a Confecção de Gráficos para Interfaces de Sites, a Validação do catálogo e do Guia de Utilização deste catálogo. A última seção descreve as Conclusões, indicando os trabalhos futuros.

\section{Fundamentação Teórica}

\subsection{Transparência Organizacional}

Impulsionada pela globalização diversas empresas, companhias, instituições disseminam a todo instante um grande volume de informações. A transparência da informação se torna fundamental para essas organizações, a fim de que os cidadãos possam acompanhar e tomar conhecimento dos fatos, de notícias que na maioria das vezes ficam escondidas dentro das organizações deixando de serem divulgadas, debatidas nas mídias, em redes sociais e em outros canais de comunicação. Nesse contexto, Barbosa et al. (2002) reiteram que a transparência de uma organização pode ser conceituada, como "A condição de abertura total dos canais de comunicação de uma organização (empresa, instituição, governo) para o público, sem qualquer cerceamento de informações". Na área da política ou econômica a transparência tornase essencial para tomadas de decisões para o bom funcionamento de uma economia, com base na disponibilização dos dados sobre a evolução econômica e financeira [FMI, 2017].

A transparência pode ser vista em algumas normativas jurídicas, como a Lei de Acesso à Informação - LAI que aborda duas formas da transparência: ativa e passiva. A "transparência ativa" refere-se, quando um determinado órgão tem iniciativa própria em divulgar informações que podem ser individuais ou coletivas, desde que não sejam sigilosas. Em contrapartida a "Transparência Passiva", obriga a um determinado órgão a prestar informações, a partir de uma solicitação do cidadão e que o sigilo não seja mantido [CGU, 2013]. Do ponto de vista do Ministério da Transparência e Controladoria-Geral da União, a transparência pode ser entendida como: um remédio para se combater a corrupção em um país, obrigando os tomadores de decisões de políticas públicas agirem com lisura e responsabilidade, permitindo que a sociedade possa acompanhar as ações do governo [CGU, 2017]. Nesse cenário foram construídos vários portais de transparência de governos, como o Portal da Transparência do governo federal [Transparência, 2017] que possibilita a sociedade civil ter acesso às informações do orçamento público financeiro, o programa "bolsa família", as despesas, as receitas, os convênios, os salários de servidores, etc., fomentando dessa forma a promoção da transparência pública. Um outro exemplo é o e-SIC (Sistema Eletrônico do Serviço de Informação ao Cidadão) que é um canal de comunicação entre o cidadão e os órgãos governamentais, onde qualquer cidadão poderá solicitar um pedido de informação a seu 
respeito e o órgão deverá responder a solicitação no prazo de 20 dias, passível de aplicação de multa pelo não cumprimento desse prazo.

Com a entrada em vigor do decreto-Lei $\mathrm{n}^{\circ}$ 8.777/2016, a transparência de uma organização pode ser acompanhada pelos cidadãos a respeito da abertura dos dados, como os "dados abertos" que pode ser compreendido, como: dados acessíveis ao público, representados em meio digital, estruturados em formato aberto, processáveis por máquina, referenciados na internet e disponibilizados sob licença aberta que permita sua livre utilização, consumo ou cruzamento, limitando-se a creditar a autoria ou a fonte [Brasil, 2017]. Algumas instituições promovem a abertura de dados abertos dos países, como o [Global Open Data Index, 2018]. A legislação nacional, gastos públicos, qualidade do ar, da água, mapas nacionais, processo eleitoral, etc., são alguns dos critérios avaliados por essa instituição atribuindo para cada critério uma pontuação. $O$ resultado dessa avaliação é uma lista que classifica os países de acordo com a soma dos pontos, como é o caso do Brasil que na última edição ficou na $8^{\circ}$ posição dentre os 94 países avaliados.

Diante desse cenário percebe-se que a transparência de uma organização tem um papel importante para o fomento de informações de qualquer organização, seja no segmento público ou privado, a fim de que qualquer tipo de cidadão possa ter acesso às informações, incluindo os deficientes visuais totais, como um estudo em portais de transparência ativa de universidades federais realizado por Ventura et al. (2015), relatando que: "apesar da disponibilização de informações públicas na internet mostrar-se uma modalidade menos custosa aos órgãos públicos e mais eficiente à sociedade, pessoas com deficiência irão encontrar diversas barreiras, pois os requisitos mínimos de e-acessibilidade não foram implementados nos portais de transparência ativa das universidades estudadas".

\subsection{Acessibilidade}

$\mathrm{Na}$ literatura há várias definições sobre o conceito de acessibilidade. O presente trabalho de pesquisa considerou a definição de Ferreira et al. (2007) que relatam: " $a$ acessibilidade consiste em oferecer ao indivíduo autonomia, mesmo que as condições fisicas ou mentais, culturais ou sociais sejam desfavoráveis, com intuito de proporcionar o acesso a lugares, estudos, serviços, transportes, meios de comunicação, tecnologias em geral e entretenimentos a todos".

Muitos esforços surgiram no final dos anos 90 para promover a acessibilidade na Internet e em ferramentas web. Um desses esforços para orientar os principais atores envolvidos no processo de construção de páginas web, como projetistas, desenvolvedores, designers foi a elaboração das diretrizes de acessibilidade, o WCAG2 (Web Content Accessibility Guidelines) [WCAG2, 2008] que foi reformulado no final do ano de 2017 e disponibilizado ao público na sua versão 2.1. Um outro exemplo é o Modelo de Acessibilidade em Governo Eletrônico que abrange quarenta e cinco recomendações e foi elaborado para atender às necessidades do governo brasileiro, visando a inclusão social de pessoas com deficiência [E-MAG, 2014]. A verificação da acessibilidade de páginas web pode ser feita de forma automática, através de ferramentas que conseguem decodificar o código HTML presente em páginas web sob a ótica das diretrizes ou recomendações de acessibilidade web [Ventura, 2015]. Um exemplo de uma ferramenta de avaliação de acessibilidade é o avaliador DaSilva [Da 
Silva, 2018]. No período de dez anos de utilização, esse avaliador realizou mais de 300.000 avaliações, registrando mais de 10.000 sites atribuindo o selo de acessibilidade de acordo com os níveis de conformidade que podem ser (A, AA ou AAA). Nas diretrizes do [WCAG21, 2017], esses níveis são referenciados, como: o nível A que é o nível mínimo, retrata que uma página web deve satisfazer todos os critérios de sucesso desse nível ou uma versão alternativa conforme fornecida; o nível AA, a página da web satisfaz todos os critérios de sucesso de nível A e nível AA, ou uma versão alternativa compatível com nível AA; e o nível AAA, a página da web satisfaz todos os critérios de sucesso de nível A, nível AA e nível AAA, ou uma versão alternativa de nível AAA conforme fornecido.

A avaliação automática sozinha não detecta todos os problemas de acessibilidade; é necessário que seja feita uma validação com humanos, tanto com a participação de especialistas como com usuários com limitações e deve ser complementada pela observação envolvendo os usuários finais [Ferreira et al. 2012]. Nesse tipo de observação podem ser identificadas características que não podem ser detectadas durante a avaliação da acessibilidade web com base em diretrizes de acessibilidade, possibilitando que se tenha um feedback dos usuários sobre $\mathrm{o}$ funcionamento de uma ferramenta ou de um site [W3C, 2010].

A acessibilidade web para os cegos é alcançada com o apoio de tecnologia assistiva definida como: "é uma área do conhecimento, de característica interdisciplinar, que engloba produtos, recursos, metodologias, estratégias, práticas e serviços que objetivam promover a funcionalidade, relacionada à atividade $e$ participação, de pessoas com deficiência, incapacidades ou mobilidade reduzida, visando a sua autonomia, independência, qualidade de vida e inclusão social" [Brasil, 2009]. Um exemplo desse tipo de tecnologia são os leitores de tela que permitem as pessoas que apresentam algum tipo de deficiência visual naveguem em sites e através de uma linguagem falada (sintetizador de voz) conseguem transmitir informações para os usuários, realizando a interpretação do código fonte HTML de uma página web. Essas tecnologias realizam a leitura de uma página web de forma sequencial no sentido da esquerda para à direita e de cima para baixo. Através do uso de teclas já programadas é possível o usuário fazer a leitura de forma fragmentada, ou seja, por palavra, linha ou parágrafo [Bach, 2009].

\subsection{Trabalhos Relacionados}

Durante a revisão bibliográfica foram identificados alguns artigos que mais se aproximam as formas alternativas de apresentar informações gráficas aos deficientes visuais totais. Alguns desses trabalhos são relatados a seguir.

Greenbacker et al. (2011) propuseram a construção de um sistema que visava a melhoria do acesso ao conteúdo de documentos multimodais contendo gráficos de linha, barras para pessoas com deficiência visual. Esse sistema tinha o propósito de reconhecer e transmitir um resumo coerente de um gráfico durante a leitura de um documento realizado por leitores de tela. Um outro software chamado de IGRAPH-Lite foi proposto por Ferres et al. (2007) permitindo que os deficientes visuais pudessem ter acesso às informações de gráficos de linhas, publicadas no "O Daily" que era o principal local de divulgação de estatísticas do Canadá. Usando uma interface baseada 
em linguagem natural inspirada em leitores de telas, pequenas descrições dos gráficos eram transmitidas para os deficientes visuais, através da sonorização.

Ferres et al. (2010) realizaram um estudo para avaliar a iteração de participantes cegos em gráficos de linha, através do uso de comandos definidos na ferramenta IGRAPH-Lite. Como resultado foram identificados que alguns comandos deveriam ser implementados para satisfazer as necessidades de acesso às informações de um gráfico para os deficientes visuais totais. Rodríguez et al. (2015) propuseram um software que utilizava uma linguagem controlada para verificar a adequação de textos alternativos as imagens, a partir de um conjunto de regras orientadas à acessibilidade direcionadas ao idioma francês. Park et al. (2016) construíram um método para extrair de forma automática um texto, a partir de uma imagem utilizando um programa de OCR (Optical Character Recognition). O texto extraído era utilizado como um texto alternativo para a imagem. Para avaliar a eficácia do método proposto, foram feitos estudos em mais de 20 sites mais acessados no mês de outubro de 2015 nos Estados Unidos que continham várias imagens. $\mathrm{O}$ resultado desse estudo comprovou que tal método, aumentou a acessibilidade na web e reduziu a carga de trabalho dos desenvolvedores web associada com as especificações de um texto alternativo.

No levantamento bibliográfico realizado, não foram identificados trabalhos com foco em características de transparência da informação que possam melhorar a apresentação e o entendimento de informações de gráficos em interfaces de sites governamentais para um grupo de cidadãos cegos.

\section{Método de Pesquisa}

O método de pesquisa foi composto por cinco etapas: A) Estudo das Características do Catálogo de Transparência; B) Identificação dos critérios do E-MAG relacionados ao entendimento de imagens por cidadãos cegos; C) Realização de um estudo de caso; D) Elaboração das recomendações; E) Validação.

A. Estudo das Características do Catálogo de Transparência: nessa etapa foi realizado um estudo das características do Catálogo de Transparência [Cappelli, 2009] formado por um SIG (Softgoal Interdependency Graph), sendo definindo como um "grafo de interpendência que desempenha um papel central na visualização analisando requisitos não funcionais - NFRs" [Marew e Dae, 2006] proporcionado a "identificação das relações de dependências entre seus elementos e suas contribuições" [Cappelli, 2009], com base nas operacionalizações e mecanismos de implementação. A partir do levantamento bibliográfico foram identificadas características de transparência que podem ser utilizadas para melhorar a compreensão de informações gráficas para os cegos.

\section{B. Identificação dos critérios do E-MAG relacionados ao entendimento de imagens} por cidadãos cegos: foram identificadas, nas recomendações do Modelo de Acessibilidade em Governo Eletrônico [E-MAG, 2014], características do Catálogo de Transparência [Cappelli, 2009] relacionadas à compreensão de imagens para os cegos, incluído as características já identificadas na etapa A. Três recomendações a 3.6 (Fornecer alternativa em texto para as imagens do sítio), a 3.11 (Garantir a leitura e compreensão das informações) e a 3.12 (Disponibilizar uma explicação para siglas, abreviaturas e palavras incomuns) podem ser aferidas da seção sobre conteúdo/informação. A característica adaptabilidade, presente na recomendação 3.6, 
determina o uso da alternativa textual ressaltando que a descrição para imagens em páginas web deve ser adaptada ao contexto da imagem. Essa característica torna-se necessária, a fim de que interfaces de sites possam ser navegáveis e compreensíveis para diversos públicos, como os deficientes visuais totais. A característica clareza pode ser destacada da recomendação 3.11 que estabelece que todo o texto possa ser entendido por usuários com baixo letramento. A recomendação 3.12 (Disponibilizar uma explicação para siglas, abreviaturas e palavras incomuns) pode-se extrair a característica explicação, necessária para que os cidadãos possam ter uma explicação dos elementos de um gráfico, como (títulos dos eixos na horizontal e vertical para os gráficos de barras ou linhas, legendas para os gráficos de pizza e outros valores).

A característica completeza implícita na recomendação 6.2 (Associar etiquetas aos seus campos) é uma importante contribuição, pois permite que os usuários possam acessar funcionalidades que já estejam disponíveis em sites, como um formulário possibilitando que esses usuários possam expressar suas opiniões, críticas, dúvidas sobre a acessibilidade as informações presentes em um gráfico. Da recomendação 1.7 (Separar links adjacentes) que define que links adjacentes devem ser separados por mais do que simples espaços para que não fiquem confusos, em especial para usuários que utilizam leitor de tela, pode-se aferir a característica intuitividade, sendo de relevante contribuição para a compreensão dos cegos que já utilizam e estão acostumados com funcionalidades que são familiares em interfaces $w e b$.

C. Realização de um estudo de caso: o estudo de caso foi conduzido por um único pesquisador que tinha experiência em mais de quinze anos em padrões $w e b$, linguagens de programação e sistemas de informação. A realização do estudo de caso compreendeu as seguintes etapas:

\section{(a) Seleção do perfil dos usuários participantes}

Foram selecionados seis cegos convocados, a partir de telefone ou pessoalmente ou convite por correio eletrônico. Para participar do estudo de caso cada voluntário teve que atender aos seguintes requisitos: ter ao menos a escolaridade de nível médio completo; possuir experiência há mais de dois anos na navegação em sites; conhecer algum gráfico estatístico do tipo (barra, linha ou pizza). Foi estabelecida a codificação da letra inicial V para manter o sigilo e anonimato das informações dos usuários. Usouse V1 para o voluntário que fez o teste-piloto e V6 para o último participante.

\section{(b) Seleção dos sites e gráficos para avaliação}

Um critério usado para a escolha dos sites foi "Possibilitar aos cidadãos o acesso às informações públicas de acordo com os dispositivos da Lei 12.527/2011 - Lei de Acesso à Informação [Brasil, Lei no 12.527 2011]". Outro critério foi "Ter sido avaliado por alguma ferramenta automática de avaliação de acessibilidade e apresentar no site o selo de acessibilidade em conformidade com os níveis AAA". Com base nesses critérios vários sites governamentais que continham imagens de gráficos estatísticos (barras, linhas e pizza) foram analisados tendo como resultado três sites selecionados que foram: Estado de São Paulo, a Prefeitura Municipal de Itupeva (http://itupeva.sp.gov.br/) que apresentou informações na forma de um gráfico de barras na vertical a respeito da evolução da população do município compreendida no período de 2000 a 2011; Ministério da Educação, a Reestruturação e Expansão das Universidades Federais (http://reuni.mec.gov.br/) que continha informações sobre a expansão das universidades criadas no interstício de 2003-2010 da rede federal de educação superior na forma de 
um gráfico de linhas; e Poder Judiciário, o Tribunal Regional do Trabalho da $1^{\text {a }}$ Região (http://trt1.jus.br/) que divulgou informações referentes ao quantitativo dos servidores do tribunal que possuíam algum tipo de deficiência/mobilidade reduzida e sobre a opinião dos servidores a respeito das condições do ambiente de trabalho, se estavam adequadas as suas necessidades no ano 2013 na forma de dois gráficos de pizza.

\section{(c) Definição do método de avaliação}

Para avaliar a interação dos voluntários, optou-se em escolher o método de observação de participantes em ambiente controlado, na forma de laboratório móvel. Os motivos para tal escolha foram: a opção por um ambiente controlado permite um controle maior na interferência de fatores externos, como ruídos, barulhos e conversas entre o participante e pessoas no ambiente de realização dos testes, que podem desviar a atenção dos usuários na execução das tarefas influenciando nos resultados dos testes.

\section{(d) Definição das tarefas}

O pesquisador definiu tarefas para serem executadas pelos participantes, visando a identificação e a compreensão das informações dispostas em gráficos (barras, linhas e pizza). As seguintes tarefas foram comuns a todos os gráficos: descrever o título e informar a fonte de publicação. Para os gráficos de barras e linhas foram: informar o título do eixo horizontal, informar o título do eixo vertical, informar o intervalo de valores no eixo horizontal e informar o intervalo de valores no eixo vertical. As tarefas informar a quantidade de barras, informar o maior valor das barras, informar o menor valor das barras foram realizadas apenas no gráfico de barras, as tarefas informar a quantidade de linhas, informar o maior valor da linha, informar o menor valor da linha no gráfico de linhas e descrever as informações da legenda, informar o valor de cada setor, informar o maior valor dos setores, informar o menor valor dos setores e informar a quantidade de setores no gráfico de pizza.

\section{(e) Execução dos testes}

Foi apresentado para cada usuário, o objetivo da pesquisa e os benefícios esperados para a execução do trabalho de pesquisa sob a forma de um "Termo de Consentimento" que poderia ser lido através de um navegador web ou pessoalmente pelo pesquisador, onde puderam ser dirimidas as dúvidas dos voluntários cegos. Um notebook portando duas caixas de som, uma câmera de vídeo integradas, um modem externo com conexão 4G para acesso a internet foi o equipamento utilizado para a realização dos testes e dois leitores de tela, o NVDA (NonVisual Desktop Access) e o DOSVOX. Escolheu-se os softwares: NVDA por ser gratuito e executado na plataforma Windows e por dispor de mais de quarenta e três idiomas [NVDA, 2016]; e o DOSVOX [DOSVOX, 2016], pela gratuidade oferecida e por ser utilizado em um dos locais de testes que foi o instituto "União dos Cegos do Brasil".

Com o propósito de coletar os dados das opiniões dos participantes, a partir de entrevista foram elaborados dois questionários (um pré-teste e outro pós-teste). Características que versaram sobre o nível de escolaridade, a profissão, a idade, o tipo de sexo, qual o grau de experiência na navegação em sites, com que frequência acessa sites governamentais e que tipo de gráficos costuma acessar foram algumas das questões abordadas no primeiro questionário (pré-testes). Já o segundo questionário abordou características a respeito das principais dificuldades enfrentadas pelos usuários no entendimento de informações nos gráficos, como por exemplo: se as informações 
presentes nos gráficos estavam claras, se houve alguma dificuldade na identificação dos títulos nos eixos horizontal e vertical nos gráficos (barras e linhas); se houve alguma dificuldade na identificação dos maiores e menores valores nos gráficos; e se as informações em um gráfico necessitavam ser mais detalhadas.

\section{(f) Análise dos resultados}

Os dados coletados dos questionários, das anotações realizadas durante a observação dos voluntários na execução das tarefas, os registros através da câmera de vídeo onde puderam ser analisadas as impressões, reações, dificuldades de entendimento e na apresentação das informações nos gráficos, serviram de insumos para a elaboração das recomendações para a confecção de gráficos em interface de sites governamentais para os cegos.

D. Elaboração das recomendações: para elaboração das recomendações foram analisados os resultados dos testes com os voluntários, na identificação de características do Catálogo de Transparência [Cappelli, 2009] e os critérios de sucesso do Modelo de Acessibilidade em Governo Eletrônico [E-MAG, 2014] que estavam relacionados ao entendimento de imagens pelos cegos. Foi elaborado um Catálogo de Entendimento de Informações Gráficas para Cidadãos Cegos, tendo como referência a notação SIG [Chung et al. 2000], onde foram definidas as operacionalizações e os mecanismos de implementação para cada característica de transparência a ser aplicada em interface de sites governamentais e um Guia explicando como o catálogo deve ser utilizado, a fim de orientar os profissionais envolvidos na publicação de informações na forma de gráficos de como devem torná-las acessíveis nestes sites.

E. Validação: os produtos gerados (Catálogo de Entendimento de Informações Gráficas para Cidadãos Cegos e o Guia de Utilização) foram entregues pessoalmente para desenvolvedores que tinham como objetivo fazer a validação em sites governamentais que atuam diretamente, das operacionalizações e mecanismos de implementação definidos nesses produtos. Para realizar a revisão das operacionalizações e mecanismos de implementação definidos para a construção de gráficos nas interfaces de sites para os cegos foram coletas opiniões, sugestões, críticas dos desenvolvedores, através de entrevistas utilizando questionários e um gravador de bolso.

\subsection{Limitações do Método}

Uma das limitações da presente pesquisa foi o fato dos testes terem sido executados apenas com leitores de tela gratuitos (DOSVOX e NVDA). Outra limitação foi o fato do estudo de caso ter se baseado somente, em gráficos do tipo (barras, linhas e pizza).

\subsection{Limitação da Pesquisa}

A pesquisa limitou-se na execução dos testes, com os leitores (DOSVOX e NVDA). Caso os testes fossem realizados com outros leitores poderiam haver alteração nos resultados. 


\section{Observações com Usuários}

\subsection{O ambiente de Testes}

O material utilizado no ambiente de testes foi: um notebook com processador (core i3 4GHZ - 1 Tera HD); uma câmera de vídeo integrada; Sistema Operacional Windows 10; dois microfones; o software de captura de tela "Icecream Screen Recorder versão 4.50"; um gravador de voz de bolso e um modem $4 \mathrm{G}$ com conexão wi-fi.

Com base nas recomendações descritas no [E-MAG, 2014] e nos padrões web (HTML5 e WAI-ARIA) foram elaborados o termo de consentimento e as tarefas exibidas em navegador web para a leitura dos participantes.

Os participantes dos testes foram dois usuários contactados durante o evento “Todos@Web" [Todos, 2016], três cegos do Instituto "União dos Cegos do Brasil" e um voluntário do Ministério Público Federal (Procuradoria da República do Rio de janeiro). Foram apresentados os leitores de tela (NVDA, DOSVOX) e os browsers (Firefox, Google Chrome e Microsoft Internet Explorer) para a realização das tarefas.

\subsection{Teste Piloto}

A usuária V1 (usuária teste) cedeu um espaço em sua residência para a realização do teste piloto. Ela optou em utilizar o teclado do notebook do pesquisador, mesmo tendo a opção de usar o teclado do seu computador; o NVDA, o sintetizador "Microsoft Speech API version 5", a voz "ScanSoft Raquel_Full_22Khz" e o navegador "Google Chrome". Os testes foram realizados no tempo total de 48 minutos e 15 segundos. Um gráfico de barras na vertical do site da Prefeitura do município de Itupeva do Estado de São Paulo (Figura 1) foi o primeiro gráfico utilizado nos testes.

Evolução da População de Itupeva

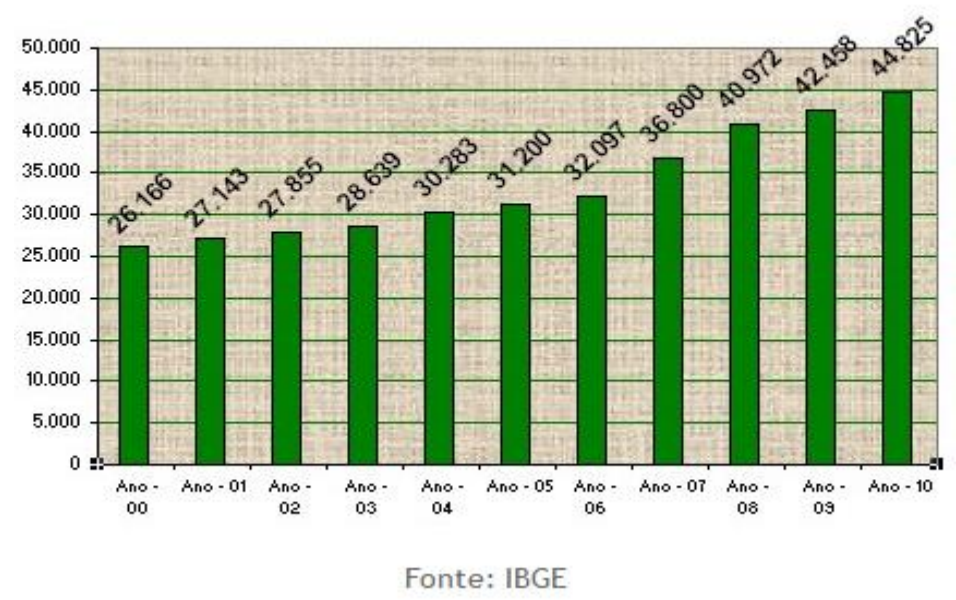

Figura 1. Evolução da população de Itupeva de 2000 a 2010, Fonte: [ITUPEVA, 2016]

Cada tarefa foi lida pelo pesquisador para a execução dos testes pela voluntária que não teve muitas dificuldades em localizar a imagem do gráfico durante a navegação no site. 


\section{Gráfico de Barras}

As tarefas descrever o título do gráfico e informar a fonte de publicação do gráfíco foram as únicas tarefas que a participante conseguiu concluir. Nas demais tarefas, ela não obteve sucesso em identificar os elementos do gráfico, pois não houve nenhuma informação descrita pelo leitor de tela.

\section{Gráfico de Linhas}

O segundo apresentado para a usuária foi um gráfico de linhas que retratou a expansão da rede federal de educação superior (Figura 2).

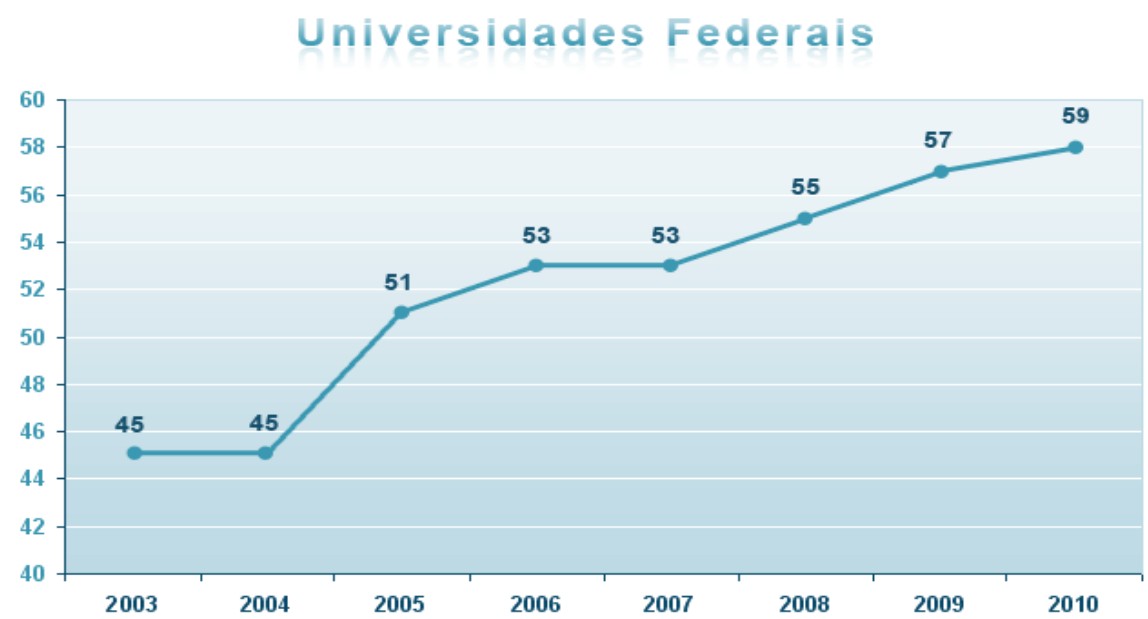

Figura 2. Expansão da rede federal de educação superior. Fonte: [REUNI, 2016]

A usuária não conseguiu executar nenhuma tarefa, pois a única informação que obteve do leitor de tela foi "gráfico expansão". Essa informação estava associada ao atributo alt da imagem do gráfico. Alguns comentários relatados pela voluntária foram: "Aonde está o gráfico?"; "Aonde estão as informações?"; "Tem um gráfico na página?"; "Essa página não tem nenhum tipo de acessibilidade!"; "O que é gráfico expansão?"; "Estou tentando qualquer coisa para obter alguma informação, inclusive utilizando a tecla tab, porém não vai!".Ao terminar os testes o pesquisador informou à usuária que havia na página um "selo de acessibilidade" e V1 explanou: "se tem o selo de acessibilidade é brincadeira, é maquiagem o que fazem com a gente que é deficiente, não colocando nenhuma informação para explicar o gráfico" 1 .

\section{Gráfico de Pizza}

Os terceiros gráficos apresentados para a voluntária foram dois gráficos de pizza que estavam dispostos em um frame (Figura 3). Dois links "Gráfico SGP .jpg" e "Baixar $18,9 \mathrm{~K}$ " estavam descritos abaixo do gráfico. Para ter acesso aos gráficos em formato ampliado em uma nova janela era necessário que o usuário clicasse em um desses links.

\footnotetext{
${ }^{1}$ Hoje em dia não se usa mais o selo de acessibilidade

${ }^{2}$ SGP - Secretaria de Gestão de Pessoal
} 


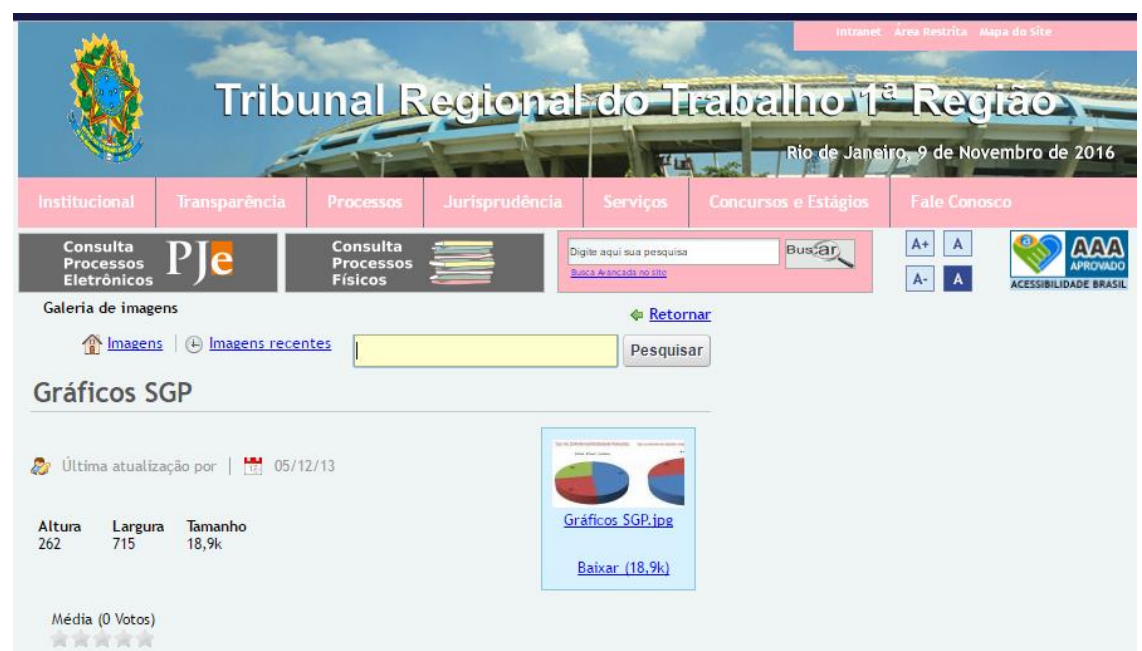

Figura 3. Tipo de deficiência/mobilidade reduzida; e sobre o ambiente de trabalho. Fonte: [TRT, 2016]

Por solicitação do pesquisador, a participante clicou no link "Gráfico SGP.jpg”, onde foram exibidos os gráficos da figura 4. O gráfico da figura 4.a apresentou informações a respeito do tipo de deficiência/mobilidade, através das cores: azul referente a deficiência física; na cor vermelha referente a deficiência visual; e na cor verde que se referia a deficiência auditiva.

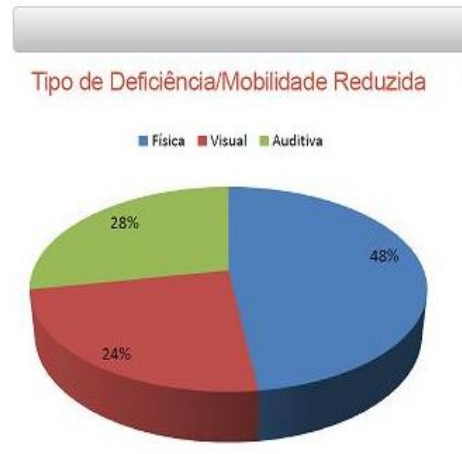

(a)

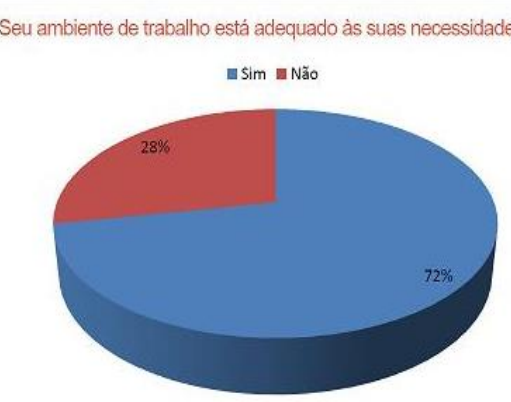

(b)

Figura 4. Gráficos ampliados. Fonte: [TRT, 2016]

No gráfico da figura 4.b foram exibidas informações sobre uma pesquisa se o ambiente de trabalho estava adequado às necessidades dos servidores do Tribunal Regional do Trabalho $-1^{\text {a }}$ Região, através de dois setores da pizza: o menor na cor vermelha representou $28 \%$ dos servidores que responderam "não", e o maior informou que $72 \%$ dos servidores responderam "sim". A participante não conseguiu realizar nenhuma tarefa, pois a única informação que obteve foi: "imagem ilustrativa" e explanou: "O que é isso, imagem ilustrativa? Imagem sem informação!"; "Ninguém merece ter acesso a nenhuma informação!"; "Para mim não tem nada para me informar!"; "Não há descrição nem nos links!"; "Aonde está o gráfico de pizza?".

\section{Entrevista pós-testes}

A voluntária respondeu questões do questionário pós-testes que visou identificar alguns componentes do gráfico, como: títulos nos eixos horizontal e vertical; legendas no gráfico de pizza; o valor de algum ponto do gráfico de linhas; o número de barras, 
linhas e setores; os maiores e menores valores e outros elementos. Todas as questões tiveram como resposta: "tive dificuldade total". Diante dessa afirmação foi necessário fazer ajustes no questionário que culminaram na reformulação de novas questões, como: quais informações gráficas que a voluntária teve dificuldade de identificar para cada tipo de gráfico (barras, linhas e pizza?). Novas tarefas identificadas pelo NVDA foram consideradas para os testes. Do gráfico de barras pode-se inferir a tarefa a respeito da data e a hora de criação do gráfico e do gráfico de pizza a tarefa sobre a data e a hora de atualização do gráfico.

\subsection{Testes com demais voluntários}

$\mathrm{O}$ segundo teste foi realizado na residência do pesquisador, a pedido do próprio participante, o V2. Os testes com os voluntários V3, V4, V5 foram realizados no "Instituto União de Cegos do Brasil". O pesquisador solicitou a um dos coordenadores do instituto para que cada participante fosse conduzido, um de cada vez, para a sala de testes, a fim de que fosse evitado alguma interferência nos resultados e comentários entre eles sobre os testes. O último participante, V6, preferiu executar os testes no seu ambiente de trabalho.

O leitor de tela utilizado pelos voluntários (V2, V3, V4, V5 e V6) foi o NVDA por ser familiar aos voluntários na navegação em sites. V2 preferiu utilizar o navegador Firefox, o sintetizador eSpeak NG e a voz Max. Os voluntários V3, V4, V5 optaram pelo browser "Google Chrome", com exceção do V6 que preferiu o "Microsoft Internet Explorer". Todos esses voluntários (V3, V4, V5 e V6) utilizaram o sintetizador "Microsoft Speech API version 5" e a voz "ScanSoft Raquel_Full_22Khz".

\section{Gráfico de Barras}

As únicas tarefas que puderam ser concluídas sem dificuldades pelos voluntários cegos foram: a descrição do título, data e hora da criação do gráfico e a fonte de publicação. As demais não foram concluídas, porque não houve descrição dos elementos do gráfico que pudessem ser lidas pelo NVDA. Durante os testes se pode coletar, dos participantes, os seguintes comentários: "Mais no gráfico em si, não tenho acesso a nada"; "O NVDA só informa: título, data, hora e fonte. E não tenho acesso a mais nada"; "O leitor não dá referência numérica alguma"; "Fala em evolução da população de Itupeva, mais quantos?"; "Ele (leitor de tela) fala da população de Itupeva, porém não descreve o gráfico"; "Não consigo ter informações"; "O leitor não descreve dados sobre o gráfico. Não entra nesse detalhe"; "Não dá informação"; "Não, não, não ouço informação"; "A descrição do gráfico aqui não tem"; "Esse detalhamento todo do gráfico sobre as informações não consigo ter"; e "Ouço população atual e o que significa?".

\section{Gráfico de Linhas}

Nenhuma tarefa pode ser concluída com sucesso pelos voluntários, pois não houve descrição do leitor de tela de nenhum componente do gráfico. A única informação que pode ser transmitida pelo leitor de tela aos voluntários foi "gráfico expansão". Os comentários registrados durante os testes foram: "Deve ser a respeito do gráfico"; "Agora a descrição sobre isso, não tem não!"; "Na verdade, o NVDA parou de falar"; "Nenhuma informação é falada mais!"; "Só ouvi: gráfico expansão"; "Deve estar sendo mostrado nessa página um gráfico com as estatísticas, não é?"; "Não dá para ler"; "Não dá para ouvir do leitor de tela pelo menos alguma coisa que seja acessível, para 
que a gente possa visualizar mentalmente"; "O leitor não me dá nenhuma informação de quantidade, de linhas, de fonte, de valores, nada!”; "O que ouço é: gráfico expansão"; "Só ouço a informação: gráfico expansão"; "Não consigo obter mais informação"; "Esse gráfico não dá descrição".

\section{Gráfico de Pizza}

A única tarefa que pode ser identificada pelo leitor de tela foi a data da última atualização do gráfico, tendo sido informada aos voluntários. Como não foram detectados outros componentes do gráfico pelo leitor de tela, os voluntários não obtiveram sucesso na conclusão das demais tarefas. Algumas das opiniões que se pode anotar dos participantes foram: "O mais perto para mim que pode ser um gráfico é a informação: gráfico SGP"; e "o leitor ficou mudo!", se referindo que não pode obter mais nenhuma informação do NVDA; "Não está falando nada"; "Tá difícil cara", "Gráfico SGP. O que é isso?"; "As informações sobre os elementos do gráfico, o que tinha no gráfico, ele (leitor de tela) não disse em nenhum momento!"; "Ficou muito a desejar!"; "O que eles colocaram na página, não corresponde com a realidade (se referindo ao selo de acessibilidade)!"; "Na verdade, ele (NVDA) não está lendo nada"; "Esse gráfico era para ele (leitor de tela) ter informado alguma coisa!" ; "Mais não leu nada!”.

\section{Entrevista pós-testes}

Ao término das entrevistas foi possível compreender melhor a experiência de cada voluntário em relação as caraterísticas de transparência, onde puderam ser obtidos os seguintes comentários: o voluntário V2 prefere escolher qual o modo de detalhamento para descrever os gráficos; o uso de teclas de atalho para obter informações sobre os títulos dos eixos horizontal e vertical, para procurar o maior e menor valor; que seja disponibilizado um formulário para sugestões; e a importância de se ter informações sobre a origem dos dados; para V3 deveriam ser implementadas as seguintes funções: opções para detalhar o gráfico na forma resumida e completa; teclas de atalho; um formulário para descrever opiniões sobre a acessibilidade do gráfico; e informações sobre a atualização dos dados; e no entendimento de V4 a página deveria ter as seguintes caraterísticas: fornecer informações do gráfico mais detalhadas; não deveriam ser programadas novas teclas de atalho para navegação, porque exige que os cegos façam um curso, para a leitura da página; ser disponibilizado um formulário para opinar sobre o gráfico; informações sobre a proveniência dos dados, como: a data, a fonte de publicação dos dados.

A voluntária V5 prefere ter informações que sejam mais detalhadas para a identificação do conteúdo no gráfico; acha necessário que sejam implementadas teclas de atalho; sugere a elaboração de um formulário para sugestões; gostaria de que fossem divulgadas informações sobre a rastreabilidade dos dados, como por exemplo: a fonte de publicação, a data e hora de disponibilização do gráfico. Já o voluntário V6 prefere que as informações sejam mais completas (detalhadas); acha complicado de se ter teclas de atalho, pois se tivesse apenas o detalhamento do gráfico seria suficiente; acha desnecessário de se ter um formulário no site, caso não hajam descrições sobre os elementos do gráfico; e não vê necessidade de publicarem informações sobre a origem dos dados. 


\section{Análise de Resultados}

Com base nas observações com os usuários durante a execução dos testes, se pode apurar as dificuldades de entendimento por eles encontradas na realização das tarefas e foram identificadas duas novas características de transparência (detalhamento e rastreabilidade).

A característica detalhamento aparece como uma importante contribuição para os cegos, pois muitos desses deficientes não têm acesso às informações detalhadas de um gráfico, como (a quantidade de barras, os intervalos entre os valores, maior e menor valor e outros elementos do gráfico).

A característica rastreabilidade é uma outra contribuição para os cegos que possibilita terem o conhecimento da proveniência das informações gráficas, como (a data, a hora da criação do gráfico, os responsáveis pela divulgação e outras informações sobre a origem dos dados).

Percebeu-se que algumas recomendações não foram atendidas pelos desenvolvedores na tentativa de os participantes obterem informações durante a realização das tarefas que não foram concluídas. Entre as recomendações não observadas no Modelo de Acessibilidade de Governo Eletrônico o [E-MAG, 2014], destaca-se a 3.6 - Fornecer uma alternativa em texto para as imagens do sítio.

Essa recomendação faz referência ao critério de sucesso do WCAG 2.0 que é a diretriz 1.1.1 e a técnica G95 do consórcio [W3C, 2008] que retratam: a diretriz 1.1.1 Conteúdo não textual: "todo o conteúdo não textual que é apresentado ao usuário tem uma alternativa textual que serve a finalidade equivalente. (Nivel A)"; e a técnica G95: "fornecer alternativas em texto abreviado que fornecem uma breve descrição do conteúdo não textual".

A utilização do atributo alt é reiterado no site [Webaim, 2016] ressaltando que esse atributo deve transmitir um conteúdo simples para descrever uma imagem. Para exemplificar a utilização da equivalência textual, isto é, o atributo alt, o trecho de código da Figura 5, ilustra o intervalo de valores no eixo horizontal e no eixo vertical do gráfico de linhas da figura 2.

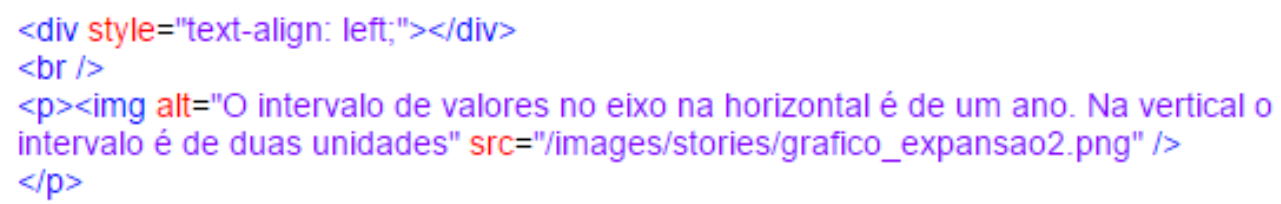

Figura 5 - Código fonte em HTML sobre o intervalo de valores do eixo na horizontal e vertical no gráfico de linhas

Uma outra forma de tornar as informações acessíveis aos cegos seria a utilização dos padrões da web como HTML5 [W3C, 2014]. Na recomendação 3.6 são descritos, os elementos (FIGURE e FIGCAPTION) do HTML5 que tem como propósito realizar o agrupamento de uma imagem com sua legenda. No trecho de código fonte em HTML (Figura 6), pode ser visto o uso desses elementos no gráfico de barras (Figura 1) a respeito das informações sobre o intervalo de valores no eixo na horizontal e no eixo na vertical. 


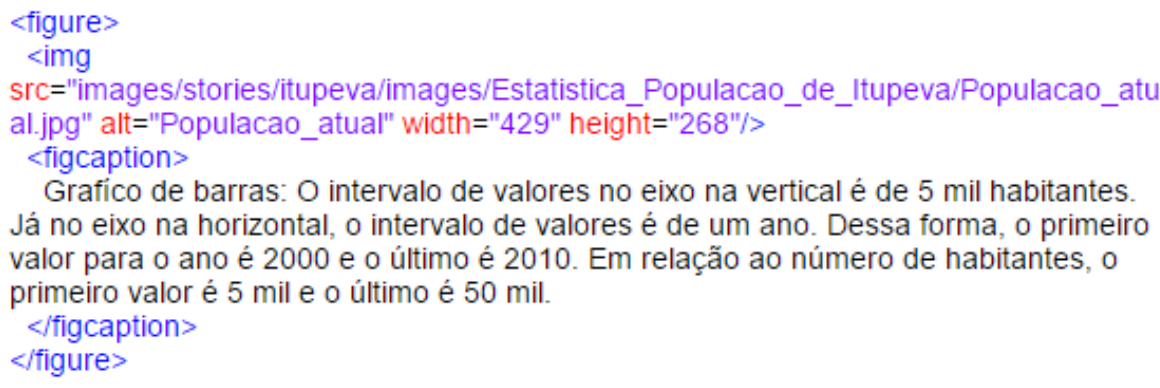

\section{Figura 6 - Código fonte utilizando os elementos FIGURE e FIGCAPTION para o intervalo entre os valores nos eixos horizontal e vertical}

Após a implementação desse trecho de código, as informações no gráfico de barras seriam exibidas, como mostra a figura 7 .

Evolução da População de Itupeva

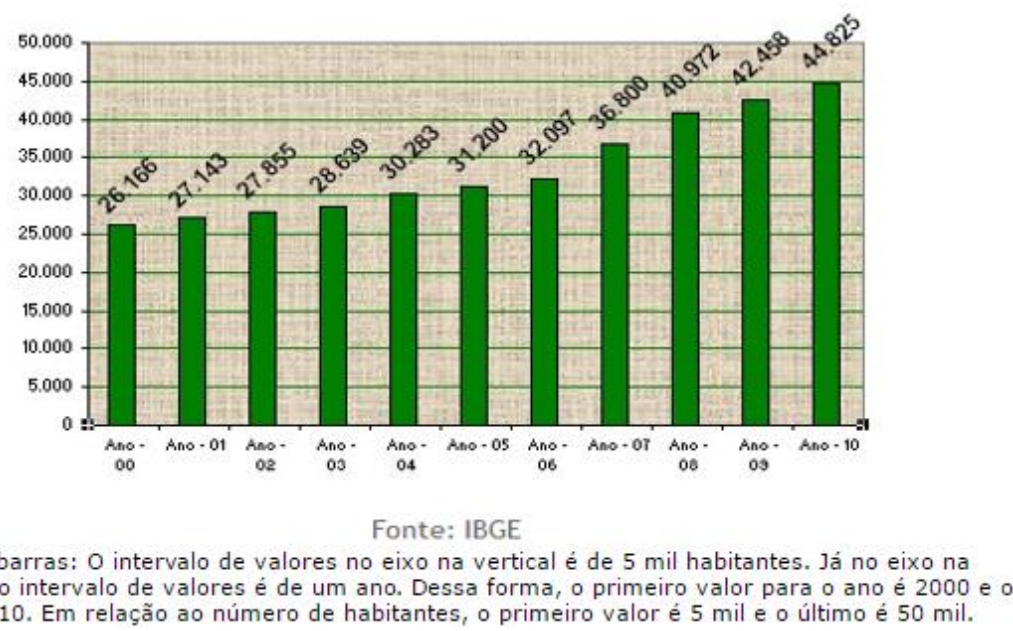

\section{Figura 7 - Gráfico de barras com descrição utilizando os elementos FIGURE e FIGCAPTION}

Para descrever informações sobre a legenda em um gráfico de pizza que possa ser detectada pelo leitor de tela em relação ao tipo de deficiência/mobilidade reduzida no gráfico de pizza (Figura 4.a) poderia ser utilizado as tags $\langle$ fieldset $>$ e $\langle$ legend $>$, como mostra a (Figura 8).

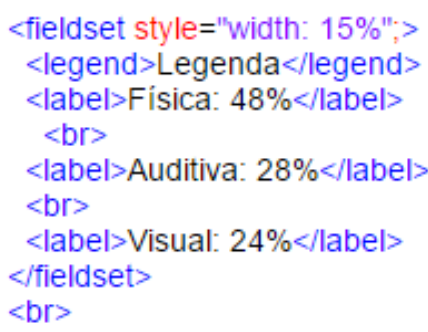

Figura 8 - Código em HTML descrevendo a legenda sobre o tipo de deficiência/mobilidade reduzida

\section{Recomendações para confecção de gráficos em interfaces de sites}

Como recomendações para confecção de gráficos em interfaces de sites foi proposto a construção de um Catálogo de Entendimento de Informações Gráficas para Cidadãos 
Cegos, contendo a definição de operacionalizações e mecanismos de implementação que podem ser aplicadas em sites governamentais; e um Guia de utilização desse catálogo, para que os profissionais envolvidos na disseminação de informações gráficas possam torná-las mais inteligíveis aos cegos.

O Catálogo de Entendimento de Informações Gráficas para Cidadãos Cegos é formado por um SIG (Softgoal Interdependency Graph) que é um grafo que possibilita a identificação das relações de dependências entre seus elementos e suas contribuições [Chung et al. 2000] e possui uma estrutura hierárquica contendo softgoals (nuvens) que são ligados através de laços de interdependência com suas operacionalizações. A elaboração desse catálogo tomou por base algumas referências: o $S I G$ de Transparência [Cappelli, 2009]; o Modelo de Acessibilidade em Governo Eletrônico [E-MAG, 2014] e opiniões e sugestões durante um estudo de caso com os voluntários cegos.

Das recomendações estabelecidas no Modelo de Acessibilidade em Governo Eletrônico [E-MAG, 2014] foram identificadas características relacionadas à compreensão de imagens por cegos que foram: adaptabilidade, clareza, completeza, explicação e intuitividade. Do estudo de caso com os participantes foram identificadas, além das características já abordadas na literatura, as características detalhamento e rastreabilidade, através dos relatos dos participantes durante a realização das tarefas e nas entrevistas.

Com base na seleção das características adaptabilidade, clareza, completeza, detalhamento, explicação, intuitividade e rastreabilidade, foi construído o SIG de Entendimento de Informações Gráficas para Cidadãos Cegos, como mostra a (Figura 9).

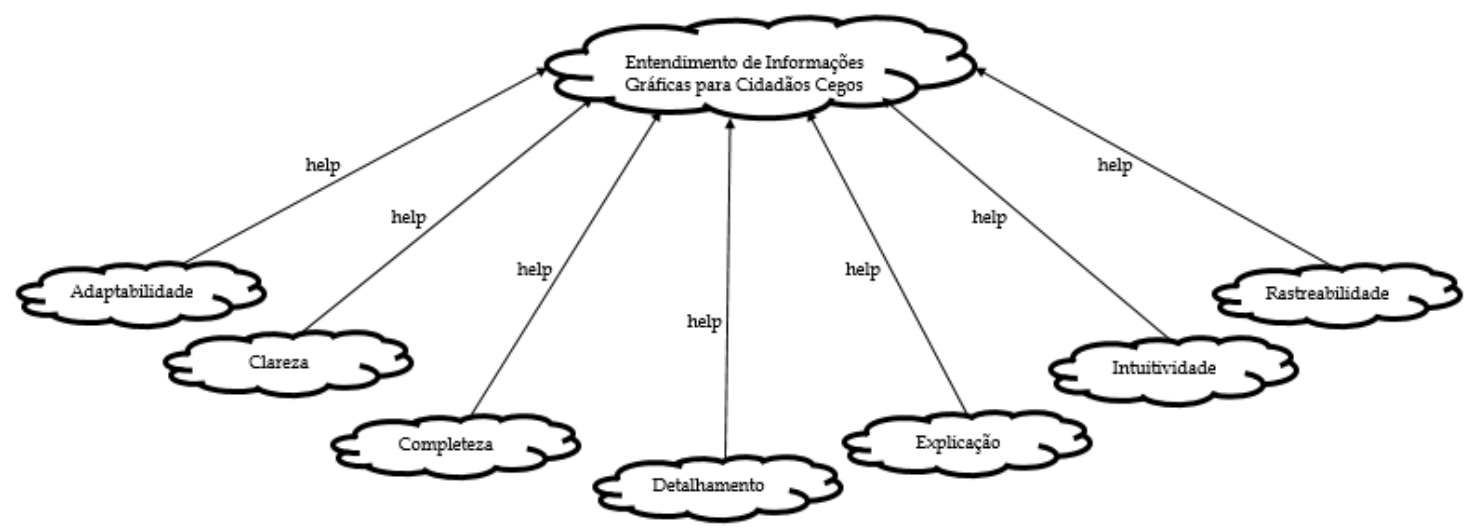

Figura 9 - SIG de Entendimento de Informações Gráficas para Cidadãos Cegos

Cada uma das características elencadas foram adaptadas do SIG de transparência [Cappelli, 2009], para o SIG de Entendimento de Informações Gráficas para Cidadãos Cegos, contendo as seguintes descrições: adaptabilidade (capacidade de apresentar informações gráficas em diferentes formatos que satisfaçam às necessidades ou mudanças de contexto.); clareza (capacidade de exibir informações gráficas de fácil compreensão); completeza (capacidade de prover informações sobre gráficos, não faltando nada que seja necessário a plena absorção do conteúdo); detalhamento (capacidade de esmiuçar as informações sobre os elementos de um gráfico); explicação (capacidade de esclarecer as informações que estejam presentes em gráficos); intuitividade (capacidade de fornecer a compreensão de informações gráficas sem a 
necessidade de um prévio aprendizado); rastreabilidade (capacidade de exibir informações sobre a proveniência dos dados utilizados na elaboração de um gráfico).

\subsection{Operacionalizações e Mecanismos de Implementação do Catálogo de Entendimento de Informações Gráficas para Cidadãos Cegos}

Foram definidas as operacionalizações e mecanismos de implementação para cada uma das características. Uma operacionalização é um conjunto de práticas que permite inserir determinada característica em um artefato para melhorar o entendimento de informações gráficas. Já os mecanismos de implementação são um conjunto de formas de implementação e exemplos de como estas práticas podem ser implementadas para melhoria do entendimento de informações gráficas [Cappelli, 2009]. As operacionalizações e mecanismos foram formulados, a partir dos relatos dos participantes. A tabela 1 mostra, as operacionalizações e os mecanismos de implementação de cada característica.

Tabela 1: Operacionalizações e mecanismos de implementação de cada caraterística

\begin{tabular}{|c|c|c|}
\hline Característica & Operacionalização & Mecanismos de Implementação \\
\hline Adaptabilidade & $\begin{array}{l}\text { Permitir a exibição de diferentes } \\
\text { maneiras de apresentação }\end{array}$ & $\begin{array}{l}\text { Disponibilizar informações sobre o } \\
\text { gráfico utilizando textos alternativos. } \\
\text { Esses textos devem ser utilizados para } \\
\text { descrever dois botões de ação: um } \\
\text { para abrir uma página descrevendo as } \\
\text { informações resumidas do gráfico e } \\
\text { outro para abrir uma página } \\
\text { descrevendo as informações gerais do } \\
\text { gráfico }\end{array}$ \\
\hline Clareza & $\begin{array}{l}\text { Descrever os elementos de um gráfico, a } \\
\text { fim de que os usuários possam } \\
\text { compreender a informação }\end{array}$ & $\begin{array}{l}\text { Descrever títulos, legendas, valores e } \\
\text { outros elementos do gráfico em uma } \\
\text { linguagem de mais fácil compreensão } \\
\text { e que possa ser acessível aos leitores } \\
\text { de tela }\end{array}$ \\
\hline Completeza & $\begin{array}{l}\text { Fornecer facilidades esperadas em uma } \\
\text { interface de site }\end{array}$ & $\begin{array}{l}\text { Disponibilizar uma página contendo } \\
\text { um formulário, para que os cegos } \\
\text { possam dar sugestões, opiniões sobre } \\
\text { o gráfico; e disponibilizar } \\
\text { informações juntos aos campos de } \\
\text { entrada de dados para preenchimento } \\
\text { e um botão de ação de submissão }\end{array}$ \\
\hline Detalhamento & Exibir informações detalhadas & $\begin{array}{l}\text { Fornecer maior valor, menor valor, } \\
\text { intervalo de valores, quantidade de } \\
\text { barras ou linhas ou setores, etc. }\end{array}$ \\
\hline Explicação & $\begin{array}{l}\text { Prover meta informação a respeito dos } \\
\text { componentes do gráfico }\end{array}$ & $\begin{array}{l}\text { Exibir um glossário para descrever as } \\
\text { siglas, as abreviaturas, os símbolos, os } \\
\text { termos técnicos utilizados na imagem } \\
\text { do gráfico }\end{array}$ \\
\hline Intuitividade & $\begin{array}{l}\text { Fornecer o acesso às informações } \\
\text { gráficas que sejam independentes de } \\
\text { qualquer tipo de software utilizado para a } \\
\text { geração de gráficos }\end{array}$ & Utilizar links \\
\hline Rastreabilidade & $\begin{array}{l}\text { Exibir os metadados de proveniência dos } \\
\text { dados gráficos }\end{array}$ & $\begin{array}{l}\text { Apresentar a data, a hora que foram } \\
\text { atualizados, criados, modificados ou } \\
\text { extraídos os dados, a entidade, órgão, } \\
\text { responsável pela divulgação, a fonte } \\
\text { ou notas sobre a publicação }\end{array}$ \\
\hline
\end{tabular}




\subsection{Guia de Utilização do Catálogo de Entendimento de Informações Gráficas para Cidadãos Cegos}

Um outro produto, fruto dessa pesquisa foi o desenvolvimento de um Guia de Utilização do Catálogo de Entendimento de Informações Gráficas para Cidadãos Cegos, contendo explicações de como aplicar as características descritas no $S I G$ de Entendimento de Informações Gráficas para Cidadãos Cegos com suas operacionalizações e mecanismos de implementação. Para usar o guia, o profissional deve consultar as características do catálogo e analisar como cada característica pode contribuir para melhorar o entendimento de alguma informação no gráfico. Após essa análise, deve avaliar quais operacionalizações podem ser utilizadas e escolher a mais aderente ao problema. Em seguida, deve verificar e escolher que mecanismos podem ser implementados. O próximo passo é realizar a implementação desses mecanismos no código fonte da página em HTML. O processo de uso do Guia de Utilização do Catálogo de Entendimento de Informações Gráficas para Cidadãos Cegos está ilustrado na (Figura 10).

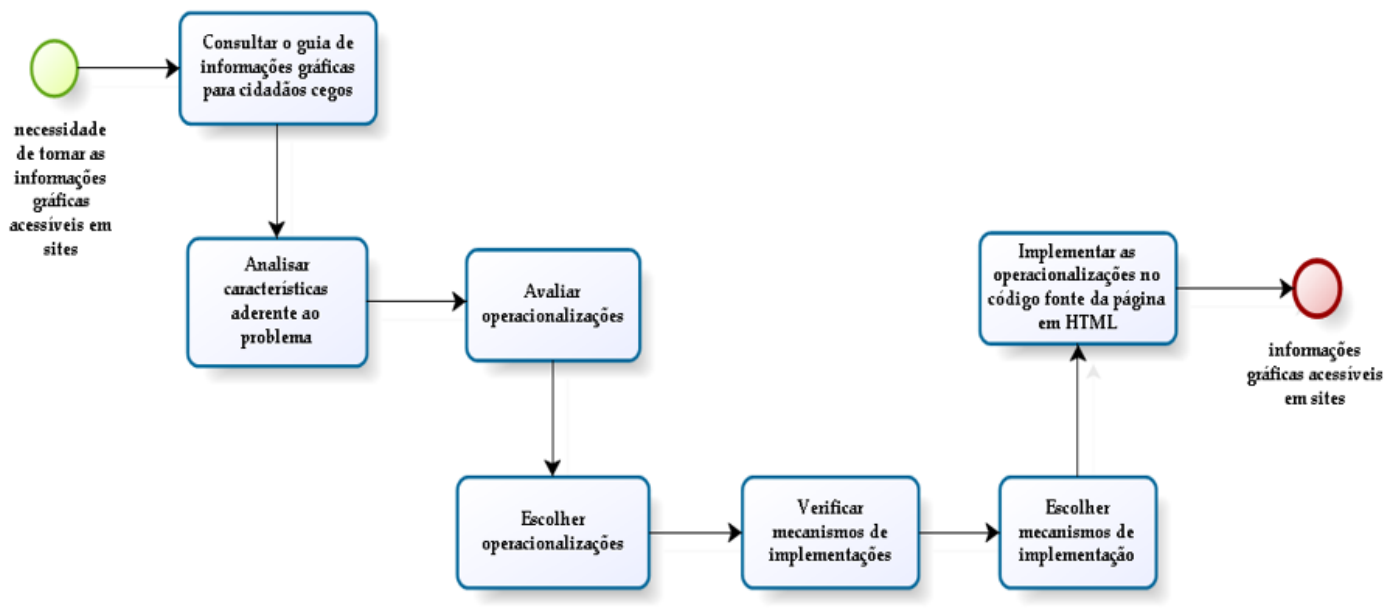

Figura 10 - Guia de Utilização do Catálogo de Entendimento de Informações Gráficas para Cidadãos Cegos

Esse trabalho de pesquisa foi apresentado para cinco servidores do Ministério do Planejamento, Desenvolvimento e Gestão da Coordenação responsável pela elaboração do E-MAG (Modelo de Acessibilidade em Governo Eletrônico) que ficou de avaliar a incorporação dos artefatos gerados na nova versão desse modelo, possibilitando que os principais atores envolvidos na construção de sites governamentais possam consultar esses artefatos e realizar a implementação, a fim de que os cegos possam ter acesso às informações de gráficos.

\subsection{Descrição do processo de como incorporar cada característica com sua operacionalização e mecanimos de implementação no código fonte da página em HTML}

A seguir é apresentado o processo de como incorporar algumas características com sua operacionalização e mecanismos de implementação no código fonte da página do site no formato HTML que contém o gráfico. 


\section{Característica Adaptabilidade}

Foi utilizada para implementação desses mecanismos a recomendação 3.6 [E-MAG, 2014] da seção conteúdo/informação que menciona: "Descrever qualquer imagem, em geral, é algo bastante subjetivo e a descrição deve ser adaptada ao contexto em que a imagem se encontra". A figura 11, mostra o resultado dos mecanismos de implementação da característica adaptabilidade.

\section{Evolução da População de Itupeva}

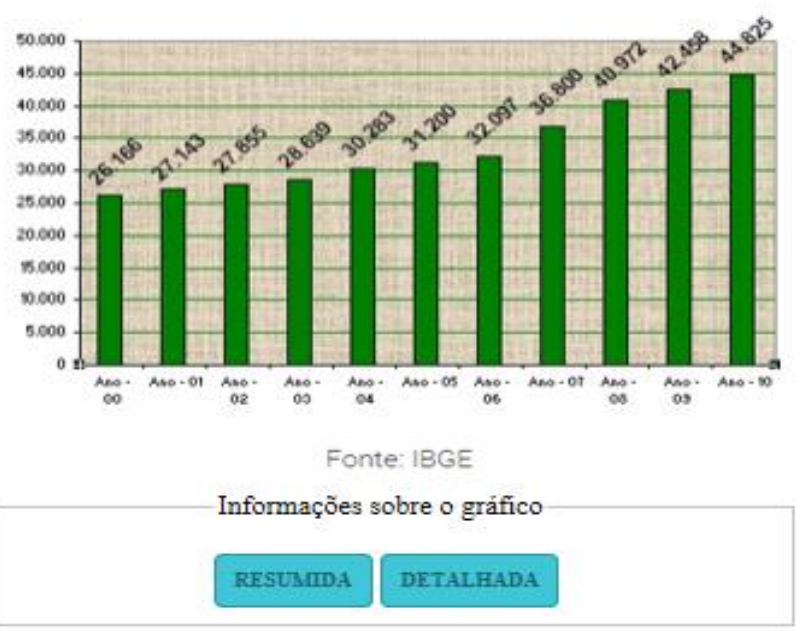

Figura 11. Resultado, da página após os mecanismos de implementação para a adaptabilidade. Fonte: coleta de dados

\section{Característica Clareza}

Para cada tipo de gráfico deve ser informado, como é sua composição e seu propósito, como por exemplo para um gráfico de barras: "os gráficos de barras são muito usados para comparar quantidades. As barras podem aparecer na vertical ou na horizontal, quando também são chamadas de colunas. Seja na horizontal ou na vertical, quanto maior o comprimento de uma barra, maior o valor que a representa. Quanto menor o comprimento de uma barra menos valor ela tem. A não ser que esteja representando números negativos, esta regra é aplicável" [Wikipédia, 2017]. Em seguida devem ser informados alguns componentes do gráfico, como (os títulos, subtítulos, legendas, valores e outros), tendo como implementação a utilização da "Recomendação 1.2 Organizar o código HTML de forma lógica e semântica" [EMAG, 2014], com HTML5 (utilizando ARIA).

\section{Característica Intuitividade}

Acesso às informações do gráfico podem ser implementadas com o uso de links. Para a implementação dos links foi utilizada a recomendação 1.7 (Separar links adjacentes), que diz: "Links adjacentes devem ser separados por mais do que simples espaços, para que não fiquem confusos, em especial para usuários que utilizam leitor de tela. Para isso, é recomendado o uso de listas, onde cada elemento dentro da lista é um link. As listas podem ser estilizadas visualmente com CSS para que os itens sejam mostrados da maneira desejada, como um ao lado do outro" [E-MAG, 2014]. A figura 12, mostra o resultado dos mecanismos de implementação da característica intuitividade. 


\section{DETALHES DO GRÁFICO}

\section{Tipo do Gráfico (abrir nova janela)}

Valores (abrir nova janela)

Origem dos dados (abrir nova janela)

Glossário (abrir nova janela)

Contato (abrir nova janela)

\section{VOLTAR}

Figura 12. Resultado, da página após os mecanismos de implementação para a intuitividade. Fonte: coleta de dados

\section{Característica Completeza}

Para implementação de um formulário levou-se em consideração a "Recomendação 6.2 - Associar etiquetas aos seus campos. As etiquetas de texto (elemento LABEL) devem estar associadas aos seus campos (elementos INPUT, SELECT e TEXTAREA, à exceção do elemento BUTTON) correspondentes no formulário, através dos atributos for do label $e$ id do input, os quais deverão ter o mesmo valor" [E-MAG, 2014]. A figura 13, mostra o resultado dos mecanismos de implementação da característica completeza.

\section{CONTATO PARA ENVIO DE OPINIÕES E SUGESTÕES}

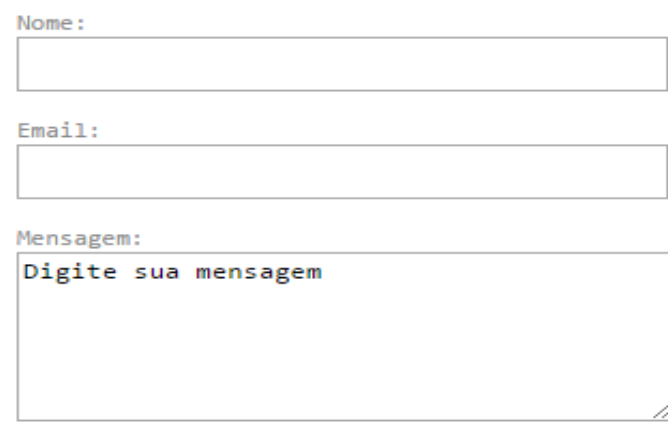

ENVIAR

vOLTAR

Figura 13. Resultado, da página após os mecanismos de implementação para a completeza. Fonte: coleta de dados

\section{Característica Detalhamento}

Algumas funcionalidades deverão ser desenvolvidas, para que os cegos possam ter acesso aos detalhes das informações gráficas. A figura 14, mostra o resultado dos mecanismos de implementação da característica detalhamento. 


\title{
INFORMAÇÕES SOBRE OS VALORES DO GRÁFICO
}

\author{
Todos os valores \\ Aqui terá uma explicação sobre todos os valores. \\ Maior e menor valor \\ Aqui terá uma explicação do maior e menor valor entre as (barras, linhas, setores) do gráfico. \\ Intervalo dos valores nos eixos (horizontal e vertical) \\ Aqui terá uma explicação sobre o intervalo dos valores no eixo vertical e horizontal. \\ Quantidade de barras, linhas e setores \\ Aqui terá uma explicação sobre a quantidade de barras ou linhas ou setores do gráfico.
}

VOLTAR

Figura 14. Resultado, da página após os mecanismos de implementação para a detalhamento. Fonte: coleta de dados

\section{Característica Explicação}

Uma página contendo um glossário deverá ser criada, para que sejam descritas informações do gráfico referentes as siglas, as abreviaturas, os símbolos e os termos técnicos. Um exemplo de implementação dessa página pode ser visto na (Figura 15), onde utilizou-se a recomendação 3.12 (Disponibilizar uma explicação para siglas, abreviaturas e palavras incomuns no texto: "Primeira ocorrência de siglas, abreviaturas ou palavras incomuns (ambíguas, desconhecidas ou utilizadas de forma muito específica), deve ser disponibilizada sua explicação ou forma completa. Essa explicação pode estar expressa no próprio texto, pode estar presente em um glossário ou, então, através da utilização do elemento abbr" que serviu de base para a implementação desses mecanismos de implementação [E-MAG, 2014].

GLOSSÁRIO - EXPLICACÃO SOBRE ABREVIATURAS, SIGLAS, SÍMBOLOS E TERMOS TÉCNICOS

Aqui terá uma explicação sobre abreviaturas, siglas, símbolos e termos técnicos.

VOLTAR

Figura 15. Resultado, da página após os mecanismos de implementação para a explicação. Fonte: coleta de dados

\section{Característica Rastreabilidade}

Para a implementação desses mecanismos foram levantados na literatura alguns metadados sobre a proveniência dos dados. O resultado da implementação pode ser visto na (Figura 16). 


\title{
INFORMAÇÕES SOBRE A ORIGEM DOS DADOS
}

\author{
Data e hora \\ Aqui terá uma explicação sobre a data, a hora da criação \\ Aqui terá uma explicação sobre a data, a hora da atualização ou modificação. \\ Aqui terá uma explicação sobre a data, a hora da extração dos dados. \\ Responsáveis pela divulgação \\ Aqui terá uma explicação sobre os responsáveis pela divulgação da publicação (unidade, setor, departamento, organização, instituição). \\ Fonte e notas de publicação \\ Aqui terá uma explicação sobre a fonte e notas da publicação (se houver).
}

\section{VOLTAR}

Figura 16. Resultado, da página após os mecanismos de implementação para a rastreabilidade. Fonte: coleta de dados

\section{Validação do Guia com Analistas Participantes}

A validação do guia compreendeu as seguintes etapas:

\section{(a) Escolha dos profissionais}

Foram selecionados três profissionais que atuaram na área de desenvolvimento de sites governamentais. A convocação desses profissionais foi realizada, através de convite por correio eletrônico ou pessoalmente. O perfil de cada analista participante atendeu aos seguintes requisitos: ter experiência no mínimo de três anos em desenvolvimento de sites do setor governamental que divulgam informações na forma de gráficos estatísticos; possuir conhecimento de algum padrão Web (HTML5, CSS, Ajax, JavaScript, JQuery, AngularJS) há pelo menos dois anos; e ter no mínimo quatro anos de experiência em alguma linguagem de programação. Para manter a confidencialidade e o anonimato das informações, esses profissionais foram codificados pela letra inicial A.

\section{(b) Seleção dos sites}

Foram analisados vários sites do IBGE que disseminam informações na forma de gráficos, onde selecionou-se três para a realização do estudo de caso: o "Banco de Dados Agregados - SIDRA" (https://sidra.ibge.gov.br/home/estoques) que apresentou informações da "Pesquisa de Estoques - $1^{\circ}$ semestre de 2016" sob a forma de um gráfico de pizza a respeito do volume, da distribuição espacial dos estoques de produtos agrícolas básicos e sobre as unidades de armazenamento; o "Sistema Integrado de Gerenciamento e Controle - SIGC" (http://w3.sigcrcivil.ibge.gov.br) que permitiu acesso aos gráficos de barras na vertical aos relatórios gerenciais para os supervisores, às coordenações técnicas para acompanhamento e tomada de decisões sobre a situação da coleta de dados nos postos; e os "Indicadores de Desenvolvimento sustentável 2014" (http://w3.ids2014.ibge.gov.br) na forma de um gráfico de linhas que forneceu subsídios para o acompanhamento da sustentabilidade do padrão de desenvolvimento brasileiro nas dimensões ambiental, social, econômica e institucional. Retratou um 
panorama abrangente de informações necessárias ao conhecimento da realidade do País, ao exercício da cidadania e ao planejamento e formulação de políticas para o desenvolvimento sustentável.

\section{(c) Resultados Obtidos}

O catálogo de entendimento de informações gráficas para os cidadãos cegos e o guia de sua utilização foram entregues aos analistas participantes, a fim de realizarem a validação das operacionalizações e mecanismos de implementação em gráficos (barras, linhas e pizza) nos sites selecionados. Elaborou-se para a coleta de dados dois questionários: o pré-testes que abordou o perfil de cada participante e o pós-testes que visou buscar as dificuldades de implementação, as sugestões e as opiniões desses profissionais em relação a implementação dos produtos gerados. Os testes com os analistas foram realizados no período de 20/03/2017 a 07/04/2017.

Em relação a experiência no desenvolvimento de sites, análise do guia de utilização, pode-se dizer, respectivamente: A1. Possuía quatro anos de experiência em sites da esfera federal, analisou o guia em três dias com base no gráfico do "Banco de Dados Agregados-SIDRA"; A2. Dez anos de experiência em sites na esfera (municipal e federal) e analisou o guia em quatro dias para implementá-lo no site do "Sistema Integrado de Gerenciamento e Controle-SIGC; e A3. Nove anos de experiência na construção de sites do segmento federal, estudou o guia durante três dias com base no site dos "Indicadores de Desenvolvimento sustentável - 2014".

\section{Entrevista pós-testes}

$\mathrm{Na}$ questão (você teve alguma dificuldade de seguir as recomendações descritas no Guia de Utilização do Catálogo de Entendimento de Informações Gráficas para Cidadãos Cegos? Quais?), as respostas que se pode obter dos profissionais foram: $A 1$. "As implementações estão bem tranquilas. O guia está bem detalhado. Não tive dificuldade de entender. São coisas que ficam isoladas em um botão direcionando para uma outra janela que não interfere diretamente no fluxo do gráfico para as pessoas que são deficientes visuais"; A2: "Para mim foi tranquilo. Não tive dificuldades. E ainda tive uma porção de ideias que podem ser feitas com a ferramenta que uso para gerar os gráficos"; e A3. "Não, não, consegui interpretar bem. Está bem detalhado".

No que concerne a questão (na sua opinião, quais são as recomendações que deveriam ser modificadas no Guia de Utilização do Catálogo de Entendimento de Informações Gráficas para Cidadãos Cegos para um melhor entendimento?), foram explanados pelos participantes: A1. "Acho que deveria ter a possibilidade de abrir na mesma página as informações sobre o gráfico e não em outra página. Poderia ser aberta uma página modal que gerasse o conteúdo de forma dinâmica"; A2. "Assim ele está bem explicado" e sugeriu que fosse utilizada uma janela pop-up acessando um javascript na mesma página ao invés de redirecionar para uma outra página. Diante dessa explanação, o pesquisador disse: esse tipo de janela deve ser evitada com base na recomendação 1.9 [E-MAG, 2014], porque os cegos não têm a noção de que foram abertas novas janelas e podem ficar perdidos buscando uma maneira de fechá-la; e em desenvolvimento web é recomendado que as informações em uma página rolem o mínimo possível e a utilização de janelas do tipo pop-up tiram o usuário do seu contexto; e A3. "Eu achei interessante, assim para a minha realidade, acho que não precisa de modificações. A aplicação que eu trabalho não é HTML puro e preciso criar 
uma janela para abrir o gráfico e colocar em um frame, porque usamos uma biblioteca em javascript, onde os elementos na tela são gerados automaticamente".

Para a questão (você utiliza alguma ferramenta para a geração de gráfico? Qual? Essa ferramenta gera código HTML?), obteve-se os seguintes relatos: A1. "Sim utilizo a biblioteca gráfica nvd3 [NVD3, 2017] que gera código no formato vetorial-SVG, que fica no fluxo do HTML com tags diferentes e o browser entende como uma imagem vetorial e rasteriza; A2. "Sim, o Highchart [HIGHCHART, 2017] que gera código do gráfico dinamicamente que ficam armazenadas dentro de funções em javaScript, onde é possivel visualizar os conjuntos de dados e metadados bastando setar um conjunto de informações, como: o tipo de gráfico (barras, linhas ou outro tipo); informar valores de dados e metadados na forma de um array"; e A3. "Então, a gente usa o gerador de gráficos do Google que já são tags em HTML, que é a biblioteca gráfica JSAPI. Essa biblioteca gera o código em HTML em forma de plug-in e eu incorporo na página do site dentro de um frame".

Em relação as respostas dos analistas para questão (como você avalia o impacto das recomendações descritas no Guia de Utilização do Catálogo de Entendimento de Informações Gráficas para Cidadãos Cegos, diante da ferramenta que utiliza para geração de gráfico?) foram registrados os seguintes comentários: A1. "É bem possível de fazer. Só seria necessário criar as páginas descritas no guia”; A2. "O impacto não é tão grande assim não, a princípio. Talvez a única restrição que vejo é personalizar a ferramenta para gerar tags em HTML que possam ser detectadas pelos leitores de tela, como a tag <alt> e outras mais especificas"; e A3. "O guia para implementar na aplicação que trabalho funcionaria na boa, não modificaria muito o que a gente trabalha. A grande questão é que os metadados do gráfico já vêm prontos da nossa área usuária que são catalogados em uma outra aplicação que consumimos, porém esses metadados são muito resumidos e não temos como interferir na descrição deles". Pode-se extrair da opinião desse analista que existem problemas no processo de construção dos gráficos e não somente na exibição das informações gráficas.

\section{(d) Revisão das operacionalizações e mecanismos de implementação definidos}

A partir dos resultados das entrevistas foram revisadas às operacionalizações e os mecanismos de implementação dos produtos gerados: catálogo e do guia de utilização para atender as necessidades de implementação desses analistas. As implementações sugeridas foram em relação a característica adaptabilidade.

\section{Analista A1}

Sugeriu que fosse aberta uma janela do tipo "modal". Foram realizadas as implementações seguindo a recomendação 1.9 [E-MAG, 2014] de como deve ser aberta esse tipo de janela de forma acessível. Analisando os resultados obtidos, após a implementação do código descrito nessa recomendação com os leitores de tela (NVDA e DOSVOX), observou-se que com o leitor NVDA não ocorreram problemas em relação a exibição das informações, na ação do usuário ao clicar em um dos botões "Resumida" ou "Detalhada" apresentados na (Figura 11). Já o leitor de tela DOSVOX não conseguiu abrir uma janela do tipo modal de acordo com o clique em um desses botões. A figura 17, mostra a tela utilizando o leitor NVDA, após o clique no botão "Resumida". 


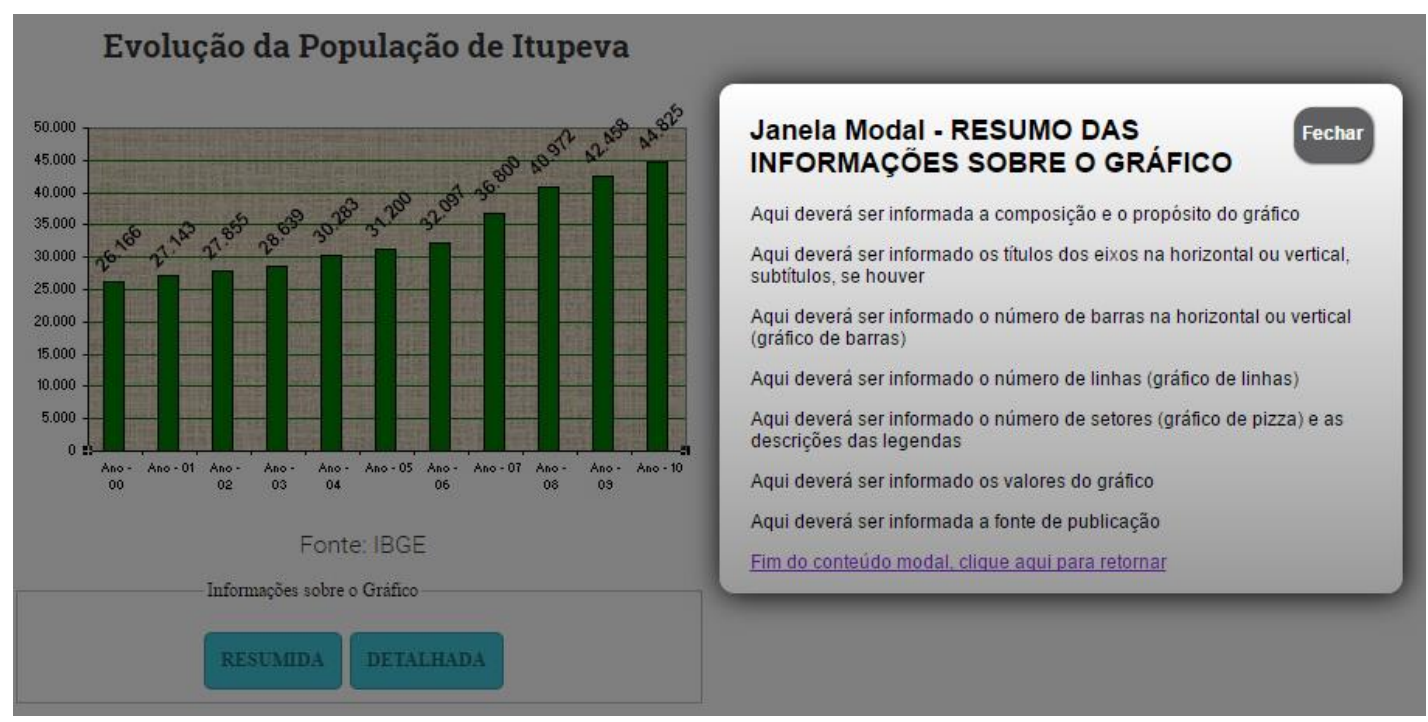

Figura 17. Abertura da janela modal, após a ação do clique no botão "Resumida" utilizando o leitor de tela NVDA. Fonte: [NVDA, 2016]

\section{Analista A2}

$\mathrm{Na}$ opinião de A2 deveria ser aberta uma janela "pop-up". Foram realizados testes nos dois leitores de tela já mencionados, a fim de que se pudesse ter uma compreensão do comportamento dessas ferramentas para a abertura desse tipo de janela. O leitor de tela [NVDA, 2016] exibiu as informações de acordo com a ação no clique dos botões. O DOSVOX não consegui ter o mesmo comportamento, ou seja, não exibiu as informações conforme a ação esperada no clique em dos botões e exibiu o mesmo conteúdo de informações, como mostra a (Figura 18).

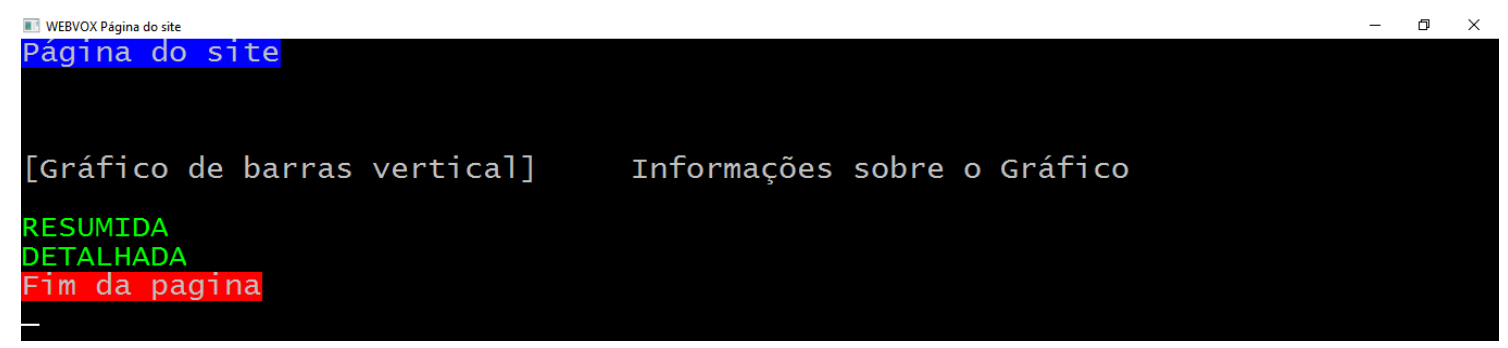

Figura 18. Leitura do código pelo leitor de tela DOSVOX, referente a abertura de uma janela pop-up. Fonte: [DOSVOX, 2016]

\section{Considerações Finais}

Esse trabalho identificou na literatura e na observação com voluntários cegos interagindo com sites governamentais a necessidade de ser ter uma maior preocupação na disponibilização de informações gráficas.

Nos artigos pesquisados, através da revisão sistemática foram encontradas algumas soluções, como: o acesso ao conteúdo de documentos multimodais contendo gráficos de linha, barras para pessoas com deficiência visual; um software utilizando linguagem natural, a fim de que os deficientes visuais pudessem ter acesso às informações de gráficos de linha; um aplicativo que utilizava uma linguagem controlada para verificar a adequação de textos alternativos as imagens, a partir de um conjunto de regras orientadas à acessibilidade do idioma francês; um método para extrair 
automaticamente um texto, a partir de uma imagem utilizando um programa de OCR (Optical Character Recognition) dando a possibilidade de ser utilizado como um texto alternativo para uma imagem. Porém, não foram encontrados trabalhos que relacionassem características de transparência da informação a acessibilidade de informações gráficas em sites web para os cegos. Dessa forma a transparência da informação aparece como uma importante contribuição para impulsionar as organizações em melhorar o entendimento dessas informações para esse grupo de cidadãos, sendo respaldadas por várias diretrizes e recomendações de acessibilidade e normas jurídicas, respectivamente, como o Modelo de Acessibilidade [E-MAG, 2014] e a Lei de Acesso à Informação [Brasil, Lei n 12.527 2011].

Foram identificadas características de transparência relacionadas a compreensão de imagens gráficas pelos cegos, a partir do estudo do catálogo de transparência [Cappelli, 2009] e do Modelo de Acessibilidade em Governo Eletrônico [E-MAG, 2014], como: adaptabilidade, clareza, completeza, detalhamento, explicação, intuitividade e rastreabilidade.

Para verificar a evidência dessas características foi realizado um estudo de caso que envolveu a participação de seis voluntários cegos que tinham experiência na navegação de sites e conhecimento de gráficos estatísticos: barras, linhas e pizza. Nesse estudo foram utilizados os leitores de tela (DOSVOX e NVDA) com intuito de detectar as dificuldades de entendimento de informações gráficas enfrentadas por esses usuários.

Analisando os resultados, a partir da coleta de dados das entrevistas de questionários, da captura de imagens da câmera de vídeo integrada a um notebook, de dois microfones, de um gravador de voz de bolso, obteve-se que $100 \%$ dos voluntários conseguiram concluir as tarefas referentes ao o título do gráfico; a data e hora da criação do gráfico; e a fonte de publicação do gráfico de barras. No gráfico de linhas nenhuma tarefa foi concluída. Já no gráfico de pizza, somente, a tarefa referente a data e hora da atualização do gráfico foi concluída com sucesso pelos participantes. As demais tarefas nos três gráficos não puderam ter sido informadas, porque não estavam descritas no código fonte em HTML da página que pudessem ser detectadas pelos leitores de tela.

Com base na observação desses voluntários durante os testes e na literatura abordada foram elaborados dois artefatos: o catálogo de entendimento de informações gráficas para cidadãos cegos, baseado na notação SIG (Softgoal Interdependency Graph) contendo a definição de operacionalizações e mecanismos de implementação das características de adaptabilidade, clareza, completeza, detalhamento, explicação, intuitividade e rastreabilidade; e o Guia de utilização do catálogo de entendimento de informações gráficas para cidadãos cegos que contém explicações de como utilizar o catálogo criado de forma a aplicar as características de entendimento de informações gráficas para cidadãos cegos com suas operacionalizações e mecanismos de implementação em gráficos.

Para realizar a validação do Guia foram selecionados três analistas profissionais que verificaram as operacionalizações e os mecanismos de implementação em gráficos de sites governamentais que atuam diretamente. As sugestões propostas por esses desenvolvedores foram revisadas e testadas nos dois leitores de tela (NVDA e DOSVOX).

Os resultados da presente pesquisa estão sendo muito úteis e foram apresentados ao Ministério do Planejamento, Desenvolvimento e Gestão para a Coordenação 
responsável pela elaboração do E-MAG (Modelo de Acessibilidade em Governo Eletrônico). Existe inclusive a possibilidade dos artefatos gerados serem incorporados na nova versão do E-MAG (Modelo de Acessibilidade em Governo Eletrônico) permitindo dessa forma que especialistas envolvidos nos projetos de construção de sites governamentais possam consultar esses artefatos, visando a implementação nesses sites que tenham algum problema de acessibilidade às informações gráficas.

\subsection{Trabalhos Futuros}

Como trabalhos futuros propõem-se alguns estudos a serem realizados por pesquisadores, projetistas de sites, como: 1. A construção de novas tags na linguagem HTML e no formato vetorial SVG que possam refletir os mecanismos de implementação de cada característica descritas no Guia de utilização do catálogo de entendimento de informações gráficas para cidadãos cegos que possam ser detectadas pelos leitores de tela; 2 . O desenvolvimento de monitores táteis que permitam os cegos acessar as descrições de informações gráficas com base nas características de transparência disponibilizadas no Guia de Utilização do catálogo de entendimento de informações gráficas para cidadãos cegos; $3 . \mathrm{Na}$ área de ecossistema de software a possibilidade de ser construída uma plataforma que tenha a participação de usuários e desenvolvedores externos que possam contribuir na concepção e preparação de sites, visando descentralizar a responsabilidade da implementação da acessibilidade às informações gráficas em páginas web normalmente ficando, somente, com os desenvolvedores da página; 4. Realização de testes com outros leitores de tela, a fim de que possam ser identificadas novas características de transparência à informação em relação a acessibilidade às informações de gráficos em sites pelos cegos.

Espera-se que os produtos gerados possam ser incorporados na linha de produção das organizações e na nova versão do Modelo de Acessibilidade em Governo Eletrônico [E-MAG, 2014], para que os cegos possam ter acesso às informações gráficas que estejam disponíveis em algumas áreas, como (a saúde, a segurança, a política), permitindo que possam compartilhar das mesmas sensações, emoções, impressões sentidas pelos videntes.

\section{Referências Bibliográficas}

Bach, C., F., (2009). Avaliação de Acessibilidade na web: estudo comparativo entre métodos de avaliação com a participação de deficientes visuais, 2009. f 200. Dissertação (Mestrado) - Universidade Federal do Estado do Rio de Janeiro, Departamento de Informática, 2009, Rio de Janeiro, 2009.

Barbosa, G.; Rabaça, A., (2002). Dicionário de Comunicação, 2 ${ }^{\text {a }}$. Ed. - Rio de Janeiro. ISBN 85-352-0854-2. Editora Campus. 2002.

Brasil, (2009). Subsecretaria Nacional de Promoção dos Direitos da Pessoa com Deficiência. Comitê de Ajudas Técnicas. Tecnologias Assistivas. http://www.pessoacomdeficiencia.gov.br/app/publicacoes/tecnologia-assistiva

Brasil, (2011) Lei $\mathrm{n}^{\mathrm{o}} 12.527$ de 18 de novembro de 2011. Regula o acesso a informações previsto no inciso XXXIII do art. 5o, no inciso II do $\S 30$ do art. 37 e no $\S 20$ do art. 216 da Constituição Federal; altera a Lei no 8.112, de 11 de dezembro de 1990; revoga a Lei no 11.111, de 5 de maio de 2005, e dispositivos da Lei no 8.159, de 8 de 
janeiro de 1991; e dá outras providências. Presidência da República, 2004, p.1. http://www.planalto.gov.br/ccivil 03/_ato2011-2014/2011/lei/112527.htm

Brasil, (2017). Decreto-Lei $n^{\circ}$ 8.777, de 11 de maio de 2016. Instituiu a Política de Dados Abertos do Poder Executivo federal. http://www.planalto.gov.br/ccivil_03/_ato2015-2018/2016/decreto/D8777.htm

Cappelli, C, (2009). Uma Abordagem para Transparência em Processos Organizacionais Utilizando Aspectos, 2009. f 329. Tese de Doutorado. Pontifícia Universidade Católica do Rio de Janeiro, Departamento de Informática, 2009, Rio de Janeiro, 2009.

Chung, L.; Nixon, B.; Yu, E.; Mylopoulos, J., (2000). Non-Functional Requirements in Software Engineering. Massachusetts.USA. Kluwer Academic Publishers. 2000.

CGU, (2013). Controladoria-Geral da União, Manual da Lei de Acesso à Informação para Estados e Municípios, $1^{\mathrm{a}}$ Edição 2013, Brasília. http://www.cgu.gov.br/Publicacoes/transparencia-publica/brasiltransparente/arquivos/manual lai estadosmunicipios.pdf

CGU, (2017). Portal do Ministério da Transparência e Controladoria-Geral da União. http://www.cgu.gov.br/

Da Silva, (2018). Avaliador de Acessibilidade Web http://www.dasilva.org.br/institucional/25/selo-de-acessibilidade

DOSVOX, (2016). Projeto DOSVOX. http://intervox.nce.ufrj.br/dosvox/download.htm

E-MAG. (2014). Modelo de Acessibilidade em Governo Eletrônico v3.1 (2014). http://emag.governoeletronico.gov.br/

Ferreira, S., B., L; Santos, R.; Silveira, D., S., (2007). Panorama da Acessibilidade na web Brasileira, Revista de Controle e Administração v.3, n.2, p.206-235, 2007.

Ferreira, S., B., L.; Silveira, D., S.; Capra, E., P.; Ferreira, A., O., (2012). Protocols for Evaluation of Site Accessibility with the Participation of Blind Users. Procedia Computer Science - 2012. - ISSN 18770509 - Volume 14 - páginas 47-45. http://www.sciencedirect.com/science/journal/18770509/14

Ferres, L.; Verkhogliad, P.; Boucher, L. (2007). (Natural language) interaction with graphical representations of statistical data. ACM International Conference Proceeding Series 225, pp. 132-133.

Ferres, L.; Lindgaard, G.; Sumegi. L., (2010). Evaluating a tool for improving accessibility to charts and graphs. ASSETS '10: Proceedings of the 12th international ACM SIGACCESS conference on Computers and accessibility.

FMI, (2017). International Monetary fund. http://www.imf.org/external/index.htm

Geraldo, J., R.; Fortes, R., P., M., (2013). Dificuldades de Usuários cegos na interação com a web: uma análise sobre as pesquisas. Revista de Sistemas e Computação, Salvador, v. 3, n. 2, p. 146-160, jul/dez. 2013.

Greenbacker, C., F.; Wu, P.; Carberry, S.; McCoy, K., F.; Elzer, S.; Mcdonald, D., D.; Chester, D.; Demir, S., (2011). Improving the accessibility of line graphs in multimodal documents. SLPAT '11: Proceedings of the Second Workshop on Speech and Language Processing for Assistive Technologies. 
Global Open Data Index (2018). https://index.okfn.org/place/

HIGHCHART, (2017). Biblioteca Gráfica. https://www.highcharts.com/

IBGE, (2016). Instituto Brasileiro de Geografia e Estatística. http://ibge.gov.br/home/estatistica/populacao/censo2010/caracteristicas_religiao_defi ciencia/default caracteristicas religiao deficiencia.shtm

ITUPEVA Prefeitura Municipal de Itupeva, (2016). Portal da Prefeitura de Itupeva, São Paulo. http://itupeva.sp.gov.br/

Marew, T.; Bae, D., H., (2006). Using Classpects for Integrating non-functional and functional requirements. Proceedings of the 24th IASTED International MultiConference Software Engineering, Innsbruck, Austria, fevereiro/2006.

NVDA, (2016). NonVisual Desktop Access. https://nvaccess.org

NVD3, (2017). Biblioteca Gráfica. http://nvd3.org

Park., E.; Lim, H., (2016). A Study on providing Alternative Text of Image for Web Accessibility Improvement. International Journal of Applied Engineering Research ISSN 0973-4562 Volume 11, Number 2 (2016) pp 762-765.

Rodríguez, S. V.; Lehmann, S., (2015). Acrolinx: a controlled-language checker turned into an accessibility evaluation tool for image text alternatives 2015 W4A '15: Proceedings of the 12th Web for All Conference.

REUNI Reestruturação e Expansão das Universidades Federais, (2016). Ministério da Educação, Brasília. http://reuni.mec.gov.br/

Takagi, H.; Ishihara, T., (2007). Technology advances and standardization toward accessible business graphics 2007. Lecture Notes in Computer Science (including subseries Lecture Notes in Artificial Intelligence and Lecture Notes in Bioinformatics).

Todos, (2016). Prêmio Nacional de Acessibilidade na Web. http://premio.ceweb.br/

Transparencia, (2017). Portal da Transparência do Governo Federal. http://www.portaltransparencia.gov.br/

TRT Tribunal Regional do Trabalho da $1^{\text {a }}$ Região, (2016). TRT1 - Rio de Janeiro. http://trt1.jus.br/

Ventura, K., S., (2015). Entre o Acessável e o Acessível: implicações dos padrões de acessibilidade para o acesso às informações públicas em universidades federais brasileiras, 2015. f 155. Dissertação (Mestrado) - Universidade Federal de Pernambuco, Departamento da Ciência da Computação, 2015, Pernambuco, 2015.

Ventura, K., S.; Siebra, S., A., (2015). e-Acessibilidade na Transparência Ativa: a aplicação das tecnologias para implementação da Lei de Acesso à Informação. Associação Nacional de Pesquisa e Pós-graduação em Ciência da Informação ANCIB, v.2 n.2. http://www.okara.ufpb.br/ojs/index.php/itec/article/view/26422

WCAG2, (2008). Web Content Accessibility Guidelines 2.0. https://www.w3.org/TR/WCAG2/

WCAG21, (2017). Web Content Accessibility Guidelines 2.1. https://www.w3.org/TR/WCAG21/

MARQUES, J. M. S.; FERREIRA, S. B. L.; CAPPELLI, C. 
WEBAIM, (2016). Web Accessibility in mind. http://webaim.org/articles/gonewild WIKIPÉDIA, (2017). The Free Encyclopedia. https://en.wikipedia.org/wiki/Freedom_of_information_laws_by_country\#Germany

$\begin{array}{llllll}\text { W3C, (2008). Técnicas para as } & \text { WCAG }\end{array}$
http://www.acessibilidade.gov.pt/w3/TR/WCAG20-TECHS/G95.html

W3C, (2010). Web Accessibility Initiative. https://www.w3.org/WAI/eval/users.html W3C, (2014). World Wide Web Consortium. https://www.w3.org/TR/htm15/

Yu, W.; Reid, D.; Brewster, S., A., (2002). Web-based Multi modal Graphs for Visually Impaired People. In, Keates, S., Eds. 1st Cambridge Workshop on Universal Access and Assistive Technology (CWUAAT), 25-27 March 2002, Cambridge, England. 